UNIVERSIDADE DE SÃO PAULO

FACULDADE DE MEDICINA DE RIBEIRÃO PRETO

DEPARTAMENTO DE NEUROCIÊNCIAS E CIÊNCIAS DO COMPORTAMENTO

STEPHANIE MARTINS DE FARIA

Efeitos da administração aguda do Canabidiol na ansiedade e nos tremores induzidos pelo teste de simulação de falar em público em pacientes com doença de Parkinson 
STEPHANIE MARTINS DE FARIA

\title{
Efeitos da administração aguda do Canabidiol na ansiedade e nos tremores induzidos pelo teste de simulação de falar em público em pacientes com doença de Parkinson
}

\author{
Dissertação de mestrado apresentada ao \\ Programa de Pós-Graduação em Saúde \\ Mental do Departamento de \\ Neurociências e Ciências do \\ Comportamento da Faculdade de \\ Medicina de Ribeirão Preto da \\ Universidade de São Paulo, para obtenção \\ do título de Mestre.
}

Área de concentração: Saúde Mental Orientador: Prof. Dr. Marcos Hortes Nisihara Chagas 
Ficha catalográfica

Serviço de documentação da Faculdade de Medicina de Ribeirão Preto - USP

Faria, Stephanie Martins de.

Efeitos da administração aguda do Canabidiol na ansiedade e nos tremores induzidos pelo teste de simulação de falar em público em pacientes com doença de Parkinson/ Stephanie Martins de Faria - Ribeirão Preto, SP, 2018. $85 \mathrm{f}$.

Dissertação (Mestrado) - Faculdade de Medicina da Universidade de São Paulo. Programa de Pós Graduação em Saúde Mental. Área de concentração: Saúde Mental.

Orientador: Marcos Hortes Nisihara Chagas.

1.Canabidiol 2.Ansiedade 3.doença de Parkinson 


\section{FOLHA DE APROVAÇÃO}

Nome: Faria, Stephanie Martins de

Título: Efeitos da administração aguda do Canabidiol na ansiedade e nos tremores induzidos pelo teste de simulação de falar em público em pacientes com doença de Parkinson

Dissertação apresentada à Faculdade de Medicina de Ribeirão Preto da Universidade de São Paulo para obtenção do título de Mestre em Ciências (Saúde Mental).

Aprovado em:

Banca Examinadora

Prof.Dr.

Instituição:

Assinatura:

Prof.Dr.

Instituição:

Assinatura:

Prof.Dr.

Instituição:

Assinatura:

Prof.Dr.

Instituição:

Assinatura:

Prof.Dr.

Instituição:

Assinatura: 


\section{DEDICATÓRIA}

Aos meus pais

pelo legado que repercute agora na universidade. 


\section{AGRADECIMENTOS}

Essa dissertação é resultado de contribuições singulares que me possibilitaram alcançar voos melhores e maiores, seria exponencialmente mais difícil sem vocês. Por isso, com gratidão especialmente agradeço:

À Deus, criador de todas as coisas, pelo respirar, inspiração e sustento no desenvolvimento deste trabalho.

Ao meu querido orientador Prof. Dr. Marcos Hortes Nisihara Chagas pela oportunidade e confiança a mim destinada há dois anos, por todo conhecimento compartilhado e paciência ao longo de meu processo de aprendizado e crescimento acadêmico.

Ao Prof. Dr. Moacir Antonelli Ponti, por topar esse desafio e gentilmente nos auxiliar a desvendar o mundo da acelerômetria.

Ao Departamento de Neurociências e Ciências do Comportamento por disponibilizar o fármaco para a utilização nesta pesquisa.

Aos colegas do grupo de pesquisa ProVive, em especial à Daiene Moraes e Madson Maximiano pela parceria e auxílio nas coletas e tabulação de dados.

Aos queridos voluntários desta pesquisa, que de forma solicita e gentil se dispuseram a participar deste estudo e transmitir mais do que respostas às avaliações, transmitir carinho e alegria aos nossos dias.

Aos coordenadores e funcionários do Departamento de Gerontologia, por abrirem as portas para a realização desta pesquisa. Em especial Mônica De Rienzo Schultz, pelo companheirismo e auxilio com os agendamentos.

À Unidade Saúde Escola por possibilitar espaços de divulgação e indicação de voluntários para a pesquisa.

À Fundação de Amparo à Pesquisa do Estado de São Paulo, pelo apoio financeiro para o desenvolvimento desta pesquisa.

À querida família Faria, em especial meus pais Edson e Valéria, que de forma fiel e amorosa me apoiaram e incentivaram em dias ensolarados, mas também dias chuvosos.

Aos meus queridos amigos da Aliança Bíblica Universitária e ADM São Carlos, pela amizade e apoio, vocês foram presentes de Deus. 


\section{RESUMO}

FARIA, S. M. (2018). Efeitos da administração aguda do Canabidiol na ansiedade e nos tremores induzidos pelo teste de simulação de falar em público em pacientes com doença de Parkinson. 2018. 85 f. Dissertação de Mestrado - Faculdade de Medicina de Ribeirão Preto, Universidade de São Paulo, Ribeirão Preto.

Introdução: O Canabidiol (CBD) é um dos principais componentes da Cannabis Sativa com propriedades ansiolíticas. Além disso, esta substância tem sido implicada na melhora de sintomas não motores da doença de Parkinson (DP), porém não foi realizado nenhum estudo para avaliar o efeito da CBD nos sintomas de ansiedade em pacientes com DP. Objetivo: O objetivo do presente estudo foi avaliar os efeitos da administração aguda de CBD na dose de 300mg nas medidas de ansiedade e nos tremores induzidos pelo teste de simulação ao falar em público em indivíduos com DP. Métodos: Foi realizado um ensaio clínico, duplo-cego, randomizado, cruzado controlado por placebo. Foram incluídos indivíduos que tivessem DP idiopática, e não estivessem em uso de benzodiazepínicos e/ou antidepressivos. Foram excluídos indivíduos com parkinsonismo atípico, demência e com diagnóstico psiquiátrico atual. Um total de24 indivíduos com DP foram incluídos e submetidos a duas sessões experimentais em um intervalo de 15 dias. Após tomar CBD ou placebo, os participantes eram submetidos ao Teste de Simulação de Falar em Público (TSFP). Durante o teste, as seguintes medidas foram coletadas: frequência cardíaca, pressão arterial sistêmica e frequência e amplitude dos tremores. Além disso, a Escala Analógica Visual de Humor (VAMS), e a Escala para Auto Avaliação ao Falar em Público (SSPS) foram aplicadas. A análise estatística foi realizada através da ANOVA de medidas repetidas considerando o fator droga, fase do TSFP e interações entre estas variáveis. Resultados: Após a análise, verificou-se que houve diferenças estatisticamente significativas no fator ansiedade da VAMS para droga $(F=6,27 ; p=0,021)$, sendo que o CBD atenuou a ansiedade experimentalmente induzida pelo TSFP. Em relação às variáveis captadas pelo acelerômetro, a ANOVA de medidas repetidas mostrou diferenças significativas para droga na variável relativa à amplitude dos tremores $(\mathrm{F}=6,19 ; \mathrm{p}=0,022)$. Não houve diferenças significativas para as demais variáveis para droga ou interação droga e fase. Conclusão: A administração aguda de CBD na dose de 300mg diminui a ansiedade em pacientes com DP e a amplitude dos tremores em situações ansiogênicas. Estudos futuros com administração crônica da CBD seriam importantes nesta população.

Palavras - chave: Canabidiol, doença de Parkinson, ansiedade, tremor. 


\begin{abstract}
FARIA, S. M. (2018). Effects of acute administration of Cannabidiol on anxiety and tremors induced by simulation test of public speaking in Parkinson's disease patients. 2018. $85 \mathrm{f}$. Dissertação (Mestrado) - Faculdade de Medicina, Universidade de São Paulo de Ribeirão Preto, Ribeirão Preto.
\end{abstract}

Introduction: Cannabidiol (CBD) is one of the main components of Cannabis sativa and has anxiolytic properties. In addition, this substance has been implicated in the improvement of non-motor symptoms of Parkinson's disease (PD), but no study has been conducted to evaluate the effects of CBD on anxiety symptoms in patients with PD. Objective: The objective of the present study was to evaluate the effects of acute CBD administration at a dose of $300 \mathrm{mg}$ on anxiety measures and tremors induced by a simulated public speaking test in individuals with PD. Methods: A randomized, double-blinded, placebo-controlled, crossover clinical trial was conducted. Individuals with idiopathic PD who were not on benzodiazepines or antidepressants were included. Individuals with atypical Parkinsonism, dementia, and a current psychiatric diagnosis were excluded. A total of 24 individuals with PD were included and underwent two experimental sessions within a 15-day interval. After taking CBD or a placebo, participants underwent the Simulated Public Speaking Test (SPST). During the test, the following data were collected: heart rate, systemic blood pressure, and tremor frequency and amplitude. In addition, the Visual Analog Mood Scales (VAMS) and Self-Statements During Public Speaking Scale (SSPS) were applied. Statistical analysis was performed by repeated-measures analysis of variance (ANOVA) while considering the drug, SPST phase, and interactions between these variables. Results: After the analysis, there were statistically significant differences in the VAMS anxiety factor for the $\operatorname{drug}(\mathrm{F}=6.27 ; \mathrm{p}=0.021)$; $\mathrm{CBD}$ attenuated the anxiety experimentally induced by the SPST. Regarding the variables recorded by the accelerometer, the repeated-measures ANOVA showed significant differences in the drug for the variable related to tremor amplitude $(\mathrm{F}=6.19 ; \mathrm{p}=0.022)$. There were no significant differences in other variables for the drug or drug-phase interaction. Conclusion: Acute CBD administration at a dose of $300 \mathrm{mg}$ decreased anxiety in patients with PD; simultaneously and the tremor amplitude in an anxiogenic situation. Future studies on the chronic CBD administration will be important in this population.

Keywords: Cannabidiol, Parkinson's disease, anxiety, tremor 


\section{LISTA DE QUADROS}

Quadro 1- Sintomas não motores da DP 17

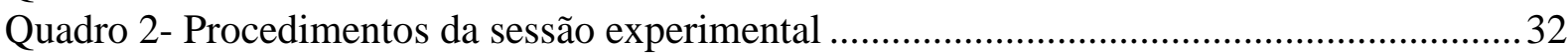




\section{LISTA DE TABELAS}

Tabela 1- Dados clínico-demográficos em pacientes com DP, Ribeirão Preto-SP, 2018 ........ 38

Tabela 2- Características clínicas da amostra estudada, Ribeirão Preto-SP, 2018. 


\section{LISTA DE FIGURAS}

Figura 1- Potenciais abordagens terapêuticas visando o sistema endocanabinóide para aliviar a

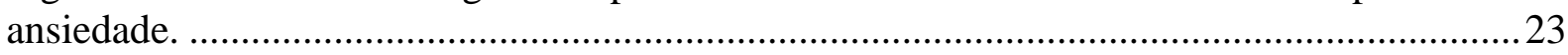

Figura 2- Comparação da administração CBD X PCB para o fator ansiedade da VAMS ....... 40

Figura 3- Comparação da administração CBD X PCB para o fator sedação mental da VAMS.

Figura 4- Comparação da administração CBD X PCB para o fator sedação física da VAMS.42

Figura 5- Comparação da administração CBD X PCB para a frequência cardíaca. ................ 43

Figura 6- Comparação da administração CBD X PCB para característica PSP.......................44 


\section{LISTA DE ABREVIATURAS E SIGLAS}

$\begin{array}{ll}\text { APA } & \text { American Psychiatry Association } \\ \text { AEA } & \text { anandamida } \\ \text { ANOVA } & \text { Análise de variância } \\ \text { BZD } & \text { benzodiazepínicos } \\ \text { CBD } & \text { Canabidiol } \\ \text { CB1 } & \text { receptores Cannabinoid 1 } \\ \text { CB2 } & \text { receptores Cannabinoid } 2 \\ \text { DP } & \text { doença de Parkinson } \\ \text { DSM } & \text { Manual de Diagnóstico e Estatístico dos Transtornos Mentais } \\ \text { FC } & \text { Frequência Cardíaca } \\ \text { FAAH } & \text { Hidrolase de ácidos graxos } \\ \text { GABA } & \text { Ácido gama-aminobutírico } \\ \text { H\&Y } & \text { Hoehn \& Hahr } \\ \text { ISRS } & \text { inibidores seletivos de recaptação de serotonina } \\ \text { MGL } & \text { lipase monoacilglicerol } \\ \text { PSE } & \text { Power Spectrum Entropy } \\ \text { PSPF } & \text { Power Spectrum PeakFrequency } \\ \text { PSP } & \text { Power Spectrum Peak } \\ \text { PA } & \text { Pressão arterial sistêmica } \\ \text { QV } & \text { Qualidade de Vida } \\ \text { S\&E } & \text { Schwab \& England } \\ \text { SSPS } & \text { Escala para e Auto Avaliação ao Falar em Público } \\ \text { SPSS } & \text { Statistical Package for the Social Sciences } \\ \text { THC } & \text { tetrahydrocannabinol } \\ \text { TT } & \text { Tapping Test } \\ \text { TCLE } & \text { Termo de Consentimento Livre e Esclarecido } \\ \text { TSFP } & \text { teste de simulação de falar em público } \\ \text { TRPV1 } & \text { transient receptor potential cation channel } \\ \text { UPDRS } & \text { Unified Parkinson's Disease Rating Scale } \\ \text { USP } & \text { Universidade de São Paulo } \\ \text { VAMS } & \text { Escala Analógica Visual de Humor } \\ \text { VR1 } & \text { Vanilloid type 1 } \\ \text { 5-HT1A } & \text { 5-hydroxytryptamine 1A } \\ \text { 8-OH-DPAT } & \text { 8-hydroxy-2-(di-n-propylamino) tetralin } \\ & \end{array}$




\section{SUMÁRIO}

1. INTRODUÇÃO ..................................................................................................................... 16

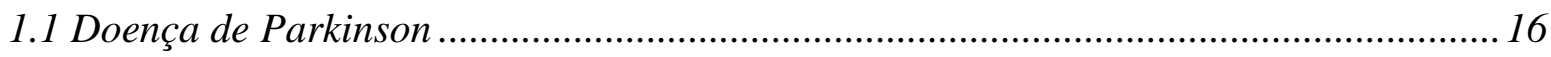

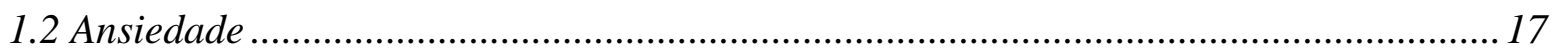

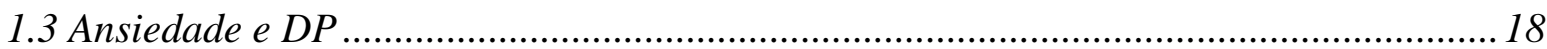

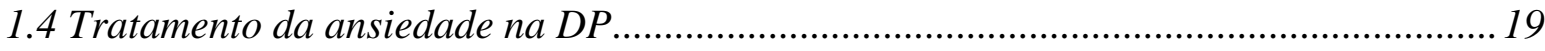

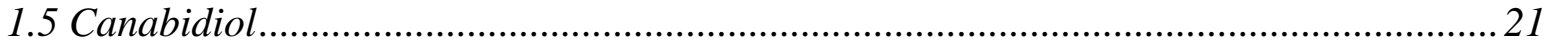

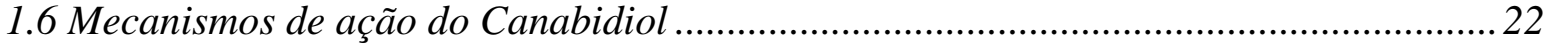

1.7 Canabidiol e potencial terapêutico na ansiedade na DP .............................................2 24

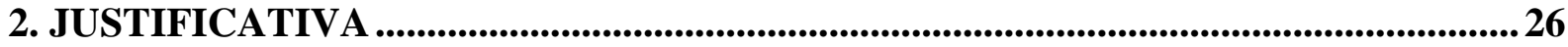

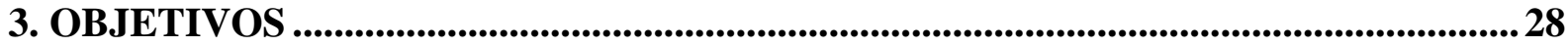

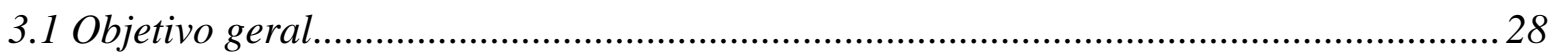

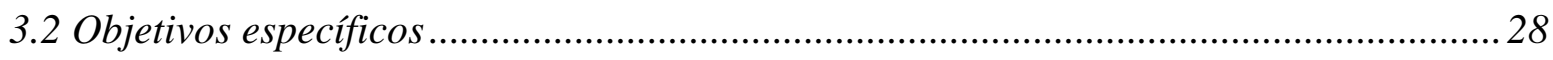

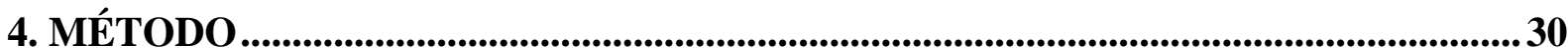

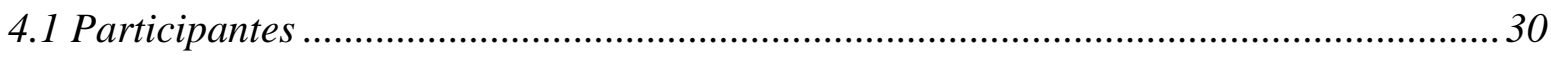

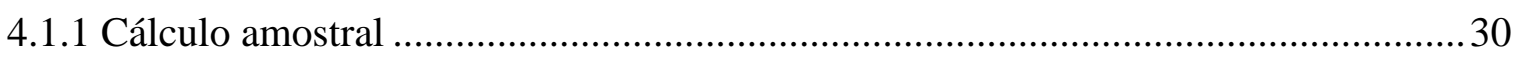

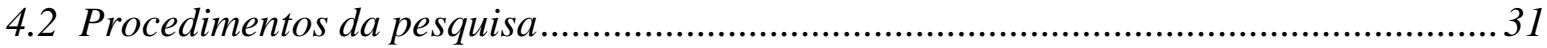

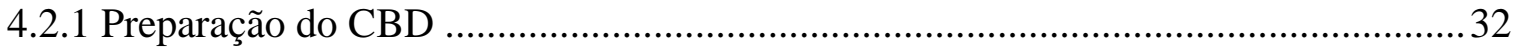

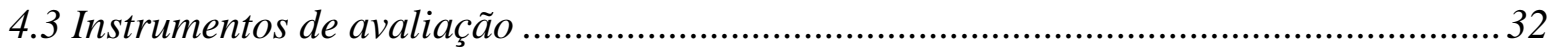

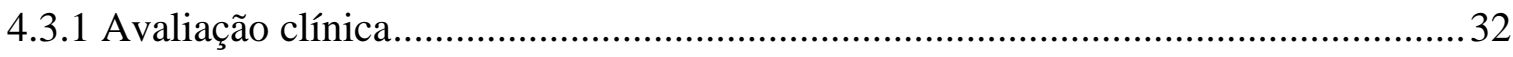

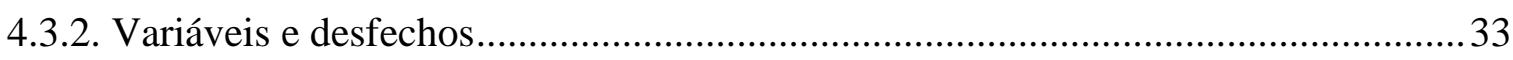

4.4 Teste de Simulação de Falar em Público (TSFP) ............................................................ 35

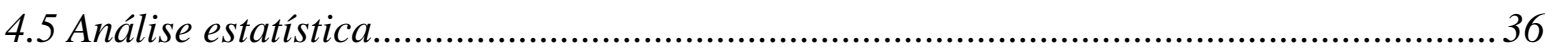

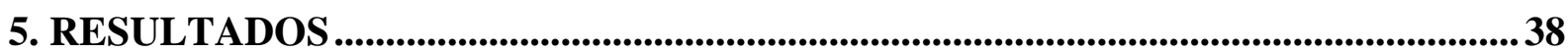

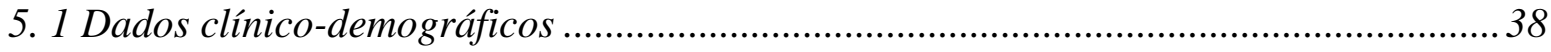

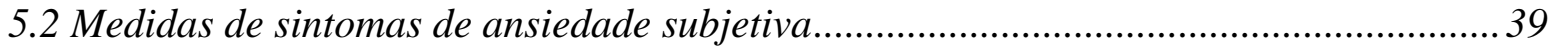

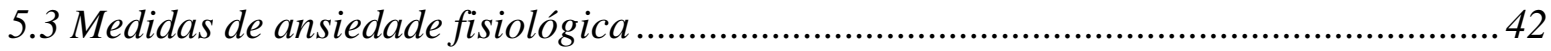

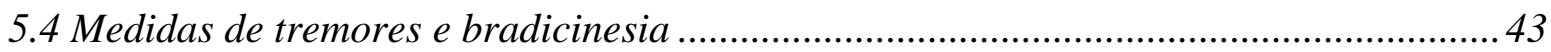




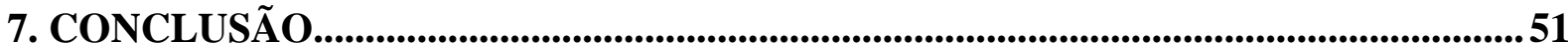

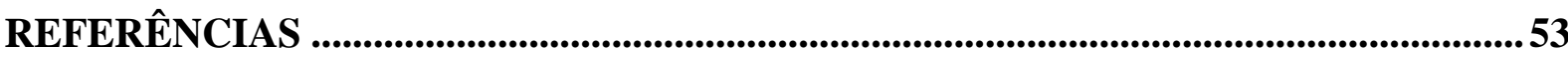

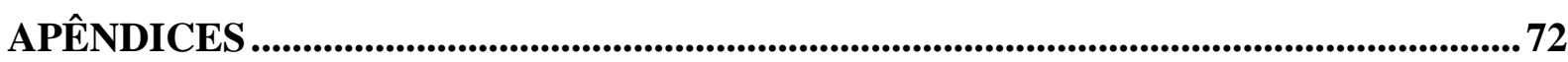

Apêndice A - Questionário de caracterização do sujeito....................................................... 72

Apêndice B - Termo de Consentimento Livre e Esclarecido................................................. 73

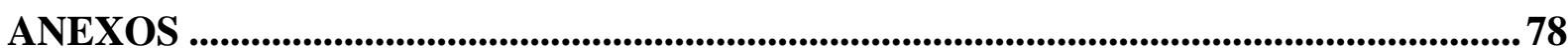

Anexo A - Escala Self-Statements during Public Speaking - Tapping Test.......................... 78

Anexo B- Escala Analógica Visual de Humor ................................................................ 79

Anexo C-Unified Parkinson's Disease Rating Scale ........................................................ 80

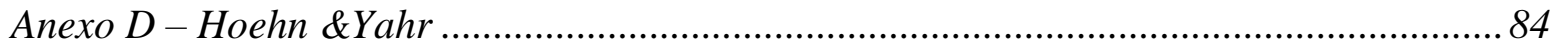




\section{INTRODUÇÃO}




\section{INTRODUÇÃO}

\subsection{Doença de Parkinson}

A doença de Parkinson (DP) é a principal causa de parkinsonismo no idoso, afetando 3,3\% da população brasileira com mais de 64 anos (Barbosa et al., 2006; Barbosa et al., 2013). Entre os distúrbios de movimento, a DP é a segunda patologia mais frequente na população idosa, atrás apenas do tremor essencial (Louis et al., 1996).

A primeira descrição da DP foi feita por James Parkinson em 1817, quando publicou "Um ensaio sobre a paralisia agitante" ("An essay on the Shaking palsy”) (Parkinson, 2016), e salientava sintomas e sinais cardinais da DP como tremores de repouso, diminuição da força muscular, posturas anormais do tronco e alterações de marcha (Kempster, Hurwitz, \& Lees, 2007). Essa descrição é muito semelhante com os critérios utilizados atualmente para o diagnóstico da DP idiopática.

O diagnóstico da DP continua essencialmente clínico e baseia-se na presença de sinais essenciais como bradicinesia, tremor em repouso, rigidez muscular e instabilidade postural, e na exclusão de outras causas de parkinsonismo como: acidente vascular encefálico, uso de medicamentos que potencialmente causem parkinsonismo, traumas cranianos e outras doenças neurológicas. Outras características clínicas relacionadas à evolução clínica devem ser consideradas para o diagnóstico como o início assimétrico, o curso crônico, a doença presente por dez anos ou mais e boa resposta ao tratamento com a levodopa (Gibb \& Lees, 1988; Hughes, Daniel, Kilford, \& Lees, 1992).

Em relação às características histopatológicas, o processo neurodegenerativo na substância negra e a consequente disfunção do sistema dopaminérgico nigro-estriatal explica uma parte os sintomas motores, no entanto a DP está relacionada à presença de inclusões citoplasmáticas anormais de $\alpha$-sinucleína imunorreativas típicas, as quais levam a formação de neurites e/ou corpos de Lewy em várias regiões do sistema nervoso. Estas inclusões desenvolvem-se dentro de neurônios específicos com distribuição ascendente (caudal-cranial) em relação ao tempo, podendo explicar o vasto leque de sinais e sintomas da DP (Braak \& DelTredici, 2008).

Apesar da relevância dos sintomas motores, atualmente, uma importância maior tem sido dada para os aspectos não motores da doença (Poewe, 2008) (tabela1), que podem acometer diversos sistemas (Chaudhuri \& Schapira, 2009; Martinez-Martin et al., 2007). 
Quadro 1- Sintomas não motores da DP

\begin{tabular}{ll}
\hline Sintomas sensoriais & Dor, disfunção olfatória, sensações anormais. \\
\hline Disfunções autonômicas & Hipotensão ortostática, constipação, disfunção \\
& urogenital. \\
Disfunções neuropsiquiátricas & Ansiedade, depressão, disfunção cognitiva e \\
& demência, psicose. \\
Disfunções gastrointestinais & Problemas dentários, disfagia, constipação, \\
& gastroparesia, refluxo gastroesofágico. \\
Distúrbio do sono & Cólicas noturnas, síndrome das pernas inquietas, \\
& alucinose, sonolência diurna. \\
\hline
\end{tabular}

Estes sintomas podem aparecer inclusive muitos anos antes do início dos sinais clássicos da DP e assumem papel fundamental na busca do diagnóstico e tratamento precoce (Rodríguez -Violante et al., 2017). Entre as manifestações não motoras da DP, os sintomas de ansiedade são extremamente comuns.

\subsection{Ansiedade}

A ansiedade é um dos estados emocionais básicos, que vem sendo estudada ao longo da história com descrições que vão desde Freud (Freud, trad., 1927) até os recentes manuais de classificação de doenças e diagnóstico em psiquiatria (World Health Organization, 2018; American Psychiatry Association [APA], 2013). Algumas definições estabelecem que a ansiedade é uma resposta desencadeada por antecipação de uma ameaça imaginada e/ou imprevisível (Swedo, Leonard \& Allen, 1994; Allen, Leonard \& Swedo, 1995; Davis, Walker, Miles \& Grillon, 2010). A ansiedade ainda pode ser compreendida por características subjetivas, comportamentais e também neurobiológicas (Wiedemann, 2015). Em humanos, podem se verificar aspectos fisiológicos relacionados à ansiedade como o aumento da pressão arterial e frequência cardíaca (Spielberger, 1979; Endler \& Kocovski, 2001).

A modulação da ansiedade está relacionada a uma complexa rede de circuitos envolvendo neurotransmissores e regiões cerebrais importantes para esse fim. No que se refere à neuroanatomia, o processamento emocional historicamente foi atribuído ao sistema límbico (Dalgleish, 2004), o qual conta com a ação de alguns neurotransmissores como a noradrenalina, serotonina, glutamato e ácido gama-aminobutírico (GABA) e estruturas cerebrais importantes, dentre as quais está a amígdala, responsável pela expressão do medo e ansiedade (Martin, Ressler, Binder \& Nemeroff, 2009; Wiedemann, 2015). Algumas estruturas relacionadas ao núcleo central da amígdala contribuem para respostas fisiológicas e comportamentais: (i) 
núcleo parabranquial, aumentando a frequência cardíaca; (ii) núcleo lateral do hipotálamo, ativando o sistema simpático;(iii) locuscoeruleus, aumentando a liberação de noradrenalina, como também aumentando da pressão arterial e o (iv) núcleo paraventricular do hipotálamo, aumentando corticosteróides (Wiedemann, 2015). O desarranjo dessas reações pode levar a quadros de ansiedade patológica como os transtornos de ansiedade (Castilho, Recondo, Asbahr \& Manfro, 2000). Ademais, os sintomas de ansiedade podem aparecer em outras doenças como é o caso da DP.

\subsection{Ansiedade e DP}

A ansiedade é altamente prevalente em pessoas com DP. Uma recente revisão da literatura mostrou que a prevalência média na DP foi de $31 \%$, com destaque para o transtorno de ansiedade generalizada, seguido de fobia social, ansiedade não especificada e fobia específica, com 14\%, 13,8\%, 13,3\% e 13\% respectivamente (Broen et al., 2016).

Possivelmente, a intersecção de múltiplos fatores como: (i) prejuízos inerentes à DP, (ii) alterações de vias relacionadas aos sistemas serotoninérgico, dopaminérgico e noradrenérgico intimamente relacionados à ansiedade, (iii) medicações utilizadas no tratamento da DP, (iv) flutuações motoras ao longo do dia e (v) comorbidade com transtornos de ansiedade são responsáveis pela prevalência elevada (Chagas et al., 2009). Lutz, Holmes, Ready, Jenkins e Johnson (2016) também apresentam aspectos que frequentemente são associados à DP, como características demográficas, sintomas motores e não motores e complicações relacionadas ao tratamento (Lutz, Holmes, Ready, Jenkins \& Johnson, 2016).

Aspectos demográficos como o gênero são importantes variáveis relacionadas à ansiedade, já que o gênero feminino é considerado um dos fatores de risco para a presença de ansiedade (Kinrys \& Wygant, 2005; Remes, Brayn, van der Linde \& Lafortune, 2016). Desta forma, os estudos têm apresentado maior prevalência de ansiedade em mulheres com DP (Fan, Chan, Wu, 2016; Liu et al., 2015; Quelhas \& Costas, 2009; Yamanishi et al., 2013).

Em relação às complicações clínicas, alguns estudos têm mostrado que a ansiedade na DP está relacionada à presença de flutuações motoras (Leentjens et al., 2012; Witjas et al., 2002, Dissanayaka et al., 2010), sendo que pacientes com flutuações motoras apresentam transtorno de ansiedade generalizada mais frequentemente do que aqueles sem flutuações motoras (Leentjens et al., 2012).

Quanto aos sintomas motores, outros estudos têm demonstrado que existe piora desses sintomas em momentos de ansiedade (Salazar, Neargarder \& Cronin-Golomb, 2017; Chagas et 
al., 2017). Um estudo recente mostrou que houve piora dos tremores quando os pacientes eram submetidos a uma situação ansiogênica, a qual parece ser independe do fenômeno on-off. Os resultados apontaram para aumento dos tremores em situação de ansiedade experimental, especificamente no teste de simulação de falar em público (TSFP). Neste estudo, pacientes com DP sem comorbidade psiquiátrica foram submetidos ao TSFP e encontrou-se piora dos tremores na fase ansiedade do TSFP (Chagas et al., 2017). Outros sintomas motores como a bradicinesia (Bolluk, Özel-Kizil, Akbostanci, \& Atbasoglu, 2010), distonia (Pontone et al., 2009) e discinesia (Dissanayaka et al, 2010) também demonstraram preditivos de altas taxas de ansiedade.

Os sintomas não motores desempenham um papel importante, já que podem associarse a ansiedade, inclusive mostrando um impacto considerável na qualidade de vida (QV) (Bugalho et al., 2016; Jones et al, 2015). Um estudo buscou identificar os fatores de risco específicos e não específicos para ansiedade na DP e encontrou que a depressão foi um dos principais fatores associados à ansiedade na DP (Cui et al., 2017). Sabe-se que a manifestação da ansiedade na DP está intimamente ligada à depressão, já que a ansiedade geralmente coexiste com depressão (Pontone et al., 2011 Yamanishi et al., 2013; Fan, Chang, Wu, 2016) e pode inclusive manifestar-se anteriormente ao aparecimento da depressão na DP (Tandberg, Larsen, Aarsland \& Cummings, 1996).

Além disso, a ansiedade tem impacto negativo na QV dos pacientes com DP (CarodArtal, Ziomkowski, Mourão Mesquita \& Martínez-Martin, 2008; Rahman, Griffin, Quinn, \& Jahanshahi, 2008; Duncan et al., 2014; Jones et al., 2015). Entender de que forma se dá esse processo considerando estas variáveis relacionadas pode contribuir para o tratamento eficaz da DP.

\subsection{Tratamento da ansiedade na DP}

$\mathrm{Na}$ DP, inibidores seletivos de recaptação de serotonina (ISRS), benzodiazepínicos (BZD), antidepressivos tricíclicos são exemplos de classes que têm sido estudadas para o tratamento da ansiedade (Menza, Marin, Kaufman, Mark \& Lauritano, 2004; Weintraub \& Burn, 2011; Connor et al., 2016). Um recente estudo investigou a eficácia de um BZD em ratos hemiparkinsonianos com ansiedade induzida. Os resultados mostraram que o fármaco possui efeito ansiolítico para ratos com baixa ansiedade, mas não para os com alta ansiedade, sugerindo que o Diazepam, o BZD testado, pode ter eficácia reduzida para indivíduos com ansiedade na DP (Connor et al., 2016). Além disso, a utilização dos BZD tem sido questionada já que seus 
efeitos colaterais exercem um considerável impacto negativo sobre a cognição, marcha, contribuindo para quedas e fraturas (Cumming \& Counteur, 2003; Schneider, Althaus, Backes \& Dodel, 2008; Connolly \& Fox, 2014), além de terem propriedades como efeito sedativo e causar dependência (Wiedemann, 2015). Uma revisão e meta-análise recente buscaram evidências do risco de uso de BZD em pessoas idosas. Os resultados apontam para um maior risco de fratura de quadril para aqueles idosos recém-prescritos com estes fármacos (Donnelly, Bracchi, Hewitt, Routledge \& Carter, 2017).

Em relação aos ISRS, um estudo duplo cego e controlado com placebo mostrou que o Citalopram diminuiu a ansiedade e o tremor, no entanto quando comparado com o grupo placebo não mostrou diferenças (Devos et al., 2008). Da mesma forma, os ISRS são amplamente utilizados, porém mesmo com a vasta utilização, é importante considerar seus efeitos colaterais no uso crônico que inclui disfunção sexual, ganho de peso, risco de doença endócrina e outros efeitos (Wolters Kluwer Health, 2012).

Outra classe de fármacos utilizada são os antidepressivos tricíclicos, estes tendem a ser mais eficazes do que os ISRSs, pois agem em duas vias neurais, compensando a perda de serotonina e noradrenalina (Weintraub \& Burn, 2011). No entanto, comparando os efeitos colaterais do desipramina, um antidepressivo tricíclico, com o cilatropam. Devos e colaboradores (2008) mostraram em seu estudo que a desipramina apresentou mais efeitos colaterais como tonturas, náuseas, constipação e hiperidrose (Devos et al., 2008).

Até o momento, o tratamento da ansiedade na DP tem considerado como foco de ação os sistemas noradrenérgico, serotoninérgico, glutamatérgico e gabaérgico (Wiedemann, 2015). Entretanto, as classes de fármacos relacionadas a esses sistemas têm apresentado efeitos colaterais importantes, além disso, existe uma escassez de estudos empíricos para o tratamento da ansiedade (Chen \& Marsh, 2014). Os estudos que têm apresentado esse efeito têm avaliado a ansiedade como desfecho secundário, com depressão sendo o principal desfecho (Menza, Marin, Kaufman, Mark \& Lauritano, 2004; Weintraub \& Burn, 2011). Nesse cenário, tem crescido o interesse pelo estudo do sistema endocanabinóide, verificando o efeito do Canabidiol (CBD) que tem se apresentado como uma alternativa terapêutica, com amplo espectro de ação, incluindo a ansiolítica, como também uma opção com menos efeitos colaterais. 


\subsection{Canabidiol}

O CBD é um dos principais componentes da planta Cannabis sativa e apresenta um amplo espectro de ação, incluindo ações hipnóticas, ansiolíticas, antipsicóticas, antiinflamatórias e neuroprotetoras (Zuardi, 2008). Apesar do isolamento do CBD do extrato da Cannabis (Adams, 1940) e da elucidação e descrição da estrutura química do CBD (Mechoulam \& Shvo, 1963) datarem mais de meio século, estes não foram suficientes para despertar o amplo interesse da comunidade científica para este canabinóide nas décadas de 70 e 80. Os escassos estudos realizados buscavam explorar as similaridades e diferenças das ações entre o CBD e a Cannabis e as interações entre os canabinóides (principalmente delta-9-THC e CBD).

No início da década de 90, o sistema endocanabinóide foi descrito e o interesse pela Cannabis foi revigorado, demonstrado pelo aumento exponencial de estudos sobre a Cannabis. Todavia, apenas no início dos anos 2000 que houve um considerável e significante crescimento dos estudos em relação ao CBD, finalmente explorando e ratificando seus diversos efeitos farmacológicos e potencial terapêutico (Zuardi, 2006).

Em relação à toxicidade, o CBD foi estudado extensivamente em animais não sendo detectados efeitos significativos (Cunha et al., 1980). Em voluntários normais, a administração aguda de CBD por via oral, inalatória ou endovenosa não produziu qualquer efeito adverso significante (Dalton, Martz, Lemberger, Rodda, \& Forney, 1976; Hollister \& Gillespie, 1975; Karniol, Shirakawa, Kasinski, Pfeferman, \& Carlini, 1974).

A administração crônica por via oral do CBD, em voluntários saudáveis, com doses de 10 a $400 \mathrm{mg} /$ dia, por até 30 dias, não produziu alterações significantes nos exames clínicos, neurológico, psiquiátrico e laboratorial, com exceção de discreta sonolência em alguns voluntários no início do tratamento (Cunha et al., 1980; Mincis et al., 1973). Em pacientes com doença de Huntington, doses diárias de CBD em torno de 700 mg durante seis semanas também não produziram efeitos tóxicos (Consroe et al., 1991). Em pacientes com DP, também não foi verificado efeitos colaterais, usando doses de $75 \mathrm{mg}$ e $300 \mathrm{mg}$ (Chagas et al., 2014). Assim, o CBD mostrou-se um composto seguro para a administração em seres humanos numa ampla faixa de dosagem, possibilitando que novos estudos fossem realizados testando seus múltiplos efeitos benéficos para a saúde. 


\subsection{Mecanismos de ação do Canabidiol}

Os efeitos do CBD estão relacionados a diferentes mecanismos de ação, os quais ainda permanecem incertos. No entanto, existe uma gama de estudos que buscam elucidar as principais vias responsáveis pelo seu amplo espectro de ação (Zuardi, 2008; Pisanti et al., 2017).

Entre estas vias e ações gerais do CBD pode-se citar: 1) Antagonismo dos agonistas $\mathrm{CB}_{1}$ e $\mathrm{CB}_{2}$ (Thomas et al., 2007); 2) Estimulação dos receptores vaniloides (VR1) com eficácia semelhante à capsaicina (agonista do VR1), dessensibilizando os receptores VR1 e desempenhando um efeito analgésico e anti-inflamatório (Bisogno et al., 2001); 3) Bloqueio da recaptação de anandamida e inibição de sua hidrólise enzimática; 4) Ação agonista nos receptores 5-hydroxytryptamine $1^{a}\left(5-\mathrm{HT}_{1 \mathrm{~A})}\right.$ (Russo, Burnett, Hall \& Parker, 2005); 5) Diminuição da recaptação de adenosina em, o que poderia levar a redução da resposta inflamatória; e 6) Ação antioxidante, que poderia estar relacionado com um possível efeito neuroprotetor (Hampson, Grimaldi, Axelrod, \& Wink, 1998).

No que se refere aos mecanismos de ação do CBD sobre sintomas de ansiedade, estudos vêm apontando para a relação entre ansiedade e o sistema endocanabinóide (Di Marzo, Bifulco, Petrocellis, 2004; Patel et al., 2017). Esse sistema é composto por ligantes endógenos, que são produzidos sobre demanda pelo próprio organismo como é o caso da anandamida (AEA) e 2arachidonoylglycerol (2-AG), e também contam com enzimas responsáveis por sua hidrólise, são elas: hidrolase de ácidos graxos (FAAH) e a lipase monoacilglicerol (MGL), respectivamente (Cravatt et al.,1996; Dinh et al., 2012). Além dos ligantes internos, temos os externos inseridos no organismo por meio de fármacos, como o tetrahydrocannabinol (THC) e CBD, que podem se ligar a receptores desse sistema (Saito, Wotjak, Moreira, 2010; Blessing et al., 2015).

Dentre os receptores, estão o Cannabinoid 1 (CB1) e Cannabinoid 2 (CB2). CB1 é um receptor localizado no sistema nervoso central, sendo encontrado em terminais pré-sinápticos, principalmente em algumas regiões cerebrais como os núcleos de saída dos gânglios de base, substância negra reticulada, córtex cerebral, hipotálamo e cerebelo (Herkenham, 1995). A depender do local cerebral que estão alocados, os receptores CB1 podem ser responsáveis pelo aprendizado, funções cognitivas e controle motor (Sagar et al, 2009). Além disso, os receptores CB1 estão abundantemente em outras regiões cerebrais, como a amígdada, responsável pelo controle da ansiedade (Herkenham et al.,1990). 
Embora o mecanismo de ação do CBD sobre a ansiedade não seja totalmente conhecido, sabe-se que possivelmente ele aja indiretamente, fazendo com que ocorra um aumento na disponibilidade de AEA na fenda sináptica, por meio da inibição da enzima FAAH, responsável pela hidrólise enzimática da AEA, a qual é responsável pela regulação dos estados emocionais (Kathuria et al., 2002; Patel et al., 2017). Outra possibilidade seria que o CBD atue antagonizando os agonistas dos receptores CB1 (Thomas et al., 2007; Patel et al., 2017) (Figura $1)$.

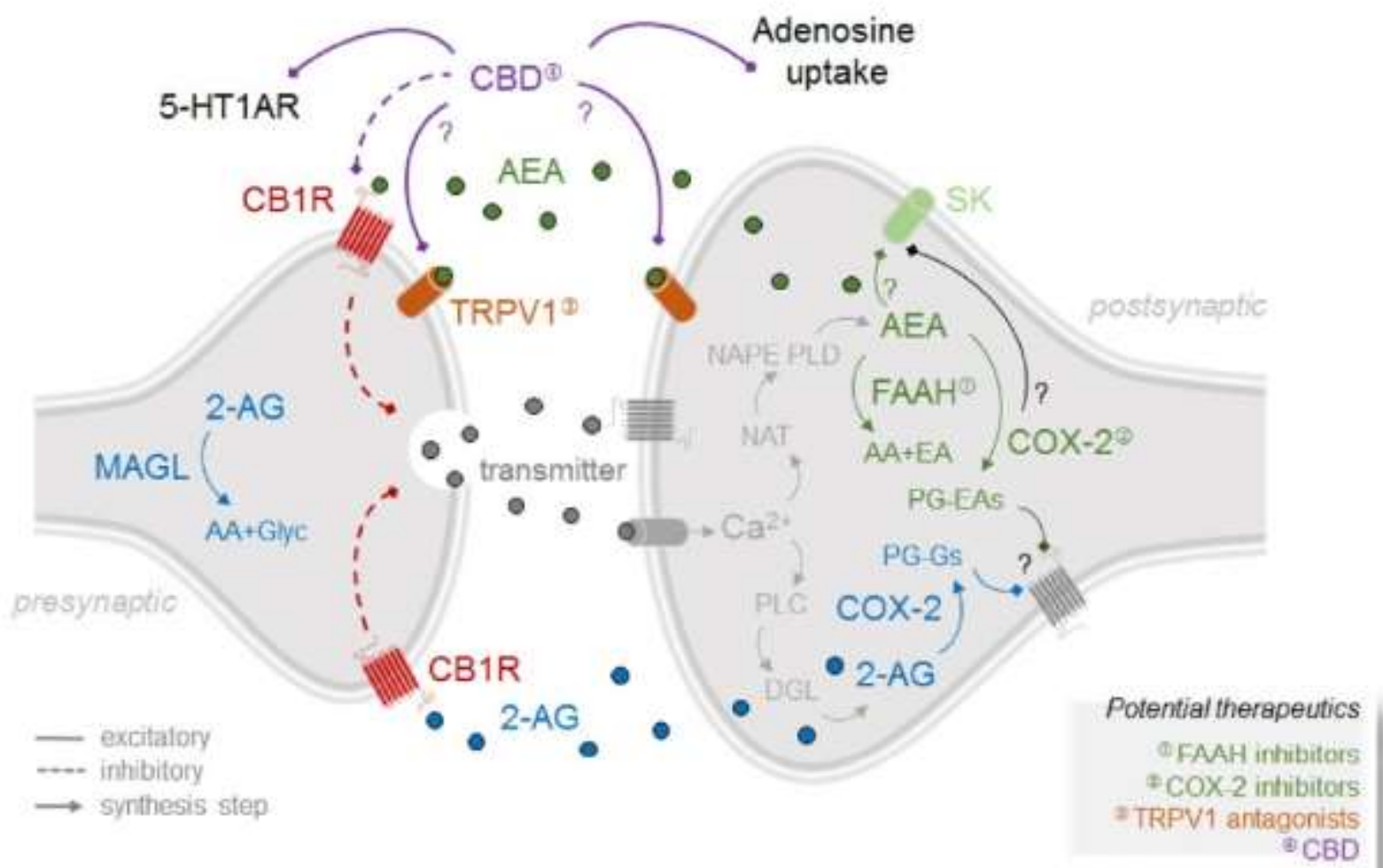

Figura 1-Potenciais abordagens terapêuticas visando o sistema endocanabinóide para aliviar a ansiedade.

Fonte: Patel, 2017, p. 58 - reprodução autorizada pelo autor.

Ao aumentar os níveis de AEA, os inibidores da FAAH modulam a liberação do transmissor e produzem efeitos anti-ansiedade, particularmente sob condições de estresse. Os inibidores de COX-2 levam ao acúmulo de níveis de AEA e podem exercer efeitos comportamentais similares aos inibidores de FAAH. O bloqueio da atividade do eCB no TRPV1 pode produzir efeitos anti-ansiedade por modulação da sinalização pré-sináptica e pós-sináptica. Finalmente, o CBD tem uma diversidade de efeitos de alívio de ansiedade que têm sido relacionados à atividade de 5-HT1AR e atualização de adenosina, bem como CB1R e potencialmente TRPV1. Receptor 5HT1A, AA = ido araquidico, $\mathrm{AEA}=$ anandamida, $\mathrm{AA}=\mathrm{Glic}=\mathrm{AA}+\mathrm{Glicina}, \mathrm{CB} 1 \mathrm{R}=$ receptor canabinóde tipo $1, \mathrm{CBD}=$ canabidiol, $\mathrm{DGL}=$ diacilglicerol lipase, $\mathrm{COX}-2=$ ciclooxigenase-2, $\mathrm{EA}=$ etanolamida, FAAH $=$ amida hidrolase de ácidos graxos, MAGL = monoacilglicerol lipase, NAPE PLD = fosfolipase D específica de N-acil fosfatidiletanolamina, NAT $=\mathrm{N}$-aciltransferase, $\mathrm{PG}-\mathrm{EA}$ = prostaglandina etanolamida, $\mathrm{PG}-\mathrm{Glic}$ = prostaglandina - glicerol, PLC = proteína lipase $\mathrm{C}, \mathrm{SK}$ - canal SK, TRPV 1 = receptor vanilóide potencial do receptor transiente tipo 1.

Outro receptor importante é o 5-HT $1 \mathrm{~A}$, ele é um receptor expresso no sistema serotoninérgico (Russo, Burnett, Hall, Parker, 2005), que de forma semelhante, tem sido estudado quanto ao efeito ansiolítico relacionado. Há indícios de que o CBD atue como um agonista direto do receptor 5-HT1A, de modo a aumentar a disponibilidade de serotonina na fenda sináptica (Russo, Burnett, Hall, Parker, 2005; Campos, Guimarães, 2008). 
Outro receptor que parece estar envolvido na mediação da ansiedade é o vanilóide tipo 1 (TRPV1), este é o receptor da capsaicina, há indicativos de que o CBD estimula o TRPV1, com um efeito similar em eficiência ao da capsaicina (Bisogno et al., 2001). Diante do cenário da possível ação do CBD sobre a ansiedade, é importante ressaltar que os mecanismos de ação do CBD estão relacionados com receptores localizados em regiões cerebrais responsáveis pela mediação da ansiedade, como é o caso da e amígdala. Deste modo, há indícios que subsidiem a hipótese de que o CBD tenha efeito sobre os sintomas de ansiedade e que possa ser uma alternativa importante e segura a ser testada na terapêutica da ansiedade na DP.

\subsection{Canabidiol e potencial terapêtico na ansiedade na DP}

Estudos já demonstraram que a administração do CBD é segura para fins terapêuticos, sendo comprovados seus efeitos anti-inflamatório, antioxidante e neuroprotetor tanto em modelo animal quanto em humanos (Booz, 2011; Campos et al., 2016; Ligresti, Petrocellis \& DiMarzo, 2016). Além disso, ele tem sido alvo de pesquisas em várias condições como: epilepsia (Pertwee, 2008), doença de Alzheimer (Cheng, Spiro, Jenner, Garner \& Karl, 2014b; Scuderi, Steardo \& Esposito, 2014), câncer (Pisanti, Picardi, D'Alessandro, Laezza \& Bifulco, 2013; Rocha, Dos Santos Júnior, Stefano \& da Silveira, 2014; Scott, Dalgleish \& Liu, 2014), doenças cardiovasculares (Stanley, Hind \& O'Sullivan, 2013), doenças inflamatórias (Mecha et al., 2013; Ribeiro et al, 2015) e DP (Zuardi et al., 2009; Chagas et al., 2014).

$\mathrm{O}$ primeiro estudo que avaliou o potencial terapêutico do CBD em pacientes com DP foi realizado por Zuardi e colaboradores (2009) e estudou as propriedades do CBD na psicose na DP. Doses entre $150 \mathrm{mg}$ a $600 \mathrm{mg}$ foram dadas a seis pacientes com sintomas psicóticos e DP, com melhora significativa dos sintomas psicóticos, além disso, foi observada diminuição dos escores totais da Unified Parkinson's Disease Rating Scale (UPDRS), sugerindo um possível efeito na DP (Zuardi et al., 2009).

Dois estudos prévios em modelos animais de parkinsonismo também apontaram neste sentido e demonstraram que a depleção de dopamina no estriado produzida pela injeção unilateral da 6-hidroxidopamina no feixe prosencefálico medial de ratos é atenuada pela administração de CBD (García-Arencibia et al., 2007; Lastres-Becker et al., 2005), sugerindo uma possível ação neuroprotetora do CBD.

Posteriormente, um estudo duplo-cego para avaliar o efeito do CBD em pacientes com DP durante seis semanas encontrou melhora significativa nos escores da escala de qualidade de vida Parkison's Disease Questionnaire-39 no grupo que recebeu CBD 300 mg comparado com o grupo placebo, principalmente nos fatores bem estar emocional e atividades de vida diária 
(Chagas et al., 2014). Apesar da exclusão de pacientes com transtornos psiquiátricos neste estudo, sintomas de ansiedade relacionados aos prejuízos inerentes da DP podem ter sido um dos responsáveis pela melhora na qualidade de vida e bem estar emocional dos pacientes.

Diversos estudos testaram o CBD em modelos de ansiedade experimental utilizando animais com a maioria dos estudos apontando para um efeito ansiolítico principalmente em doses menores (de Mello Schier et al., 2014). Um dos primeiros estudos foi realizado por Guimarães et al. (1990) (Guimarães, Chiaretti, Graeff, \& Zuardi, 1990) e testaram o efeito da administração de CBD em ratos no modelo de ansiedade do labirinto em cruz elevado comparando quatro doses de CBD, diazepam e veículo e encontraram efeito ansiolítico em três doses de CBD testadas comparável com o diazepam. Estudos com administração direta de CBD em substância periaquedutal cinzenta também apontaram para os mesmos resultados (Campos \& Guimarães, 2008), de forma que parece consistente o efeito do ansiolítico do CBD em modelos animais.

Em relação aos estudos com humanos, a primeira evidência de efeitos do CBD em sintomas psicológicos, mais especificamente na ansiedade, foi encontrada por Zuardi et al. (1982). Neste estudo, foi observado que o CBD poderia atenuar os efeitos ansiogênicos do THC. Considerando este possível efeito ansiolítico, Zuardi e colaboradores (1993) realizaram um estudo para comparar o efeito do CBD no TSFP comparando com outras drogas ansiolíticas como diazepam e ipsapirone e demonstram mais uma vez que o CBD poderia ter um efeito ansiolítico na dose de 300 mg (Zuardi, Cosme, Graeff, \& Guimarães, 1993).

Posteriormente, um estudo para testar o efeito do CBD especificamente em sujeitos com transtorno de ansiedade social foi conduzido, apontando para menores níveis de ansiedade, sintomas somáticos e auto avaliação negativa no grupo que recebeu CBD na dose de $600 \mathrm{mg}$ comparado com o grupo que recebeu placebo (Bergamaschi et al., 2011). Estudos de neuroimagem também foram realizados para avaliar o efeito do CBD na dose de $400 \mathrm{mg}$ e encontraram um aumento de atividade cerebral no giro para-hipocampal esquerdo e diminuição no complexo amígdala-hipocampo esquerdo, compatível com um padrão de efeito ansiolítico no SPECT (Crippa et al., 2004; Crippa et al., 2011).

Ainda, um recente estudo realizado por Zuardi e colaboradores (2017), a fim de verificar o efeito ansiolítico do CBD em indivíduos saudáveis, nas doses de 100 mg, 300 e 900 mg, comparado ao clonazepam e placebo, mostrou que as medidas de ansiedade subjetivas foram reduzidas na dose de 300 mg, mas não com 100 mg e 900 mg, pós teste de indução da ansiedade. Além disso, esse efeito ansiolítico observado segue o padrão de uma curva invertida em forma de U, assim como em estudos de modelo animal (Zuardi et al., 2017). 


\section{JUSTIFICATIVA}

A alta prevalência de sintomas de ansiedade nos indivíduos com DP e a piora dos sintomas motores com o aumento dos níveis de ansiedade apontam para a necessidade de tratamentos que atuam nestes sintomas. $\mathrm{O}$ CBD em administração aguda já mostrou ser seguro e também capaz de diminuir os sintomas de ansiedade em sujeitos saudáveis e com transtornos de ansiedade. Desta forma, avaliar os efeitos da administração aguda do CBD nos sintomas de ansiedade e tremores de pacientes com DP, se mostra importante para a pesquisa e para a prática clínica. 
OBJETIVOS 


\section{OBJETIVOS}

\subsection{Objetivo geral}

Avaliar os efeitos da administração aguda de CBD na dose de $300 \mathrm{mg}$ nas medidas de ansiedade (subjetivas e fisiológicas) e nos tremores induzidos pelo TSFP em indivíduos com DP.

\subsection{Objetivos específicos:}

$\checkmark$ Verificar as diferenças entre os grupos CBD e placebo nos sintomas de ansiedade subjetiva nas diferentes fases do TSFP;

$\checkmark$ Verificar as diferenças entre os grupos CBD e placebo nos sintomas de ansiedade fisiológica nas diferentes fases do TSFP;

$\checkmark$ Verificar as diferenças entre os grupos CBD e placebo nos tremores no TSFP obtidos pelos acelerômetros;

$\checkmark$ Avaliar possíveis efeitos adversos do CBD durante o TSFP. 
MÉTODO 


\section{MÉTODO}

O presente estudo é um ensaio clínico randomizado, duplo-cego e cruzado. Dessa forma, os participantes foram distribuídos randomicamente para receber CBD ou placebo no primeiro experimento. $\mathrm{O}$ intervalo entre o primeiro e segundo experimento foi de 15 dias. Durante este período as medicações em uso pelo paciente não poderiam ser alteradas. No dia do primeiro experimento foi explicado o Termo de Consentimento Livre e Esclarecido (TCLE). O projeto possui a autorização do Comitê de Ética em Pesquisa da Universidade Federal de São Carlos, parecer 1.631.701; de modo a respeitar integralmente a Resolução CNS 466/12 e suas complementares.

\subsection{Participantes}

Foram selecionados 24 voluntários com DP idiopática, identificados a partir de chamada pública nos meios de imprensa do município de São Carlos e em alguns dos serviços de Neurologia da cidade de São Carlos e região.

\subsubsection{Cálculo amostral}

Um estudo prévio realizado por nosso grupo (Chagas et al., 2017) avaliou pacientes com DP no TSFP e encontrou na fase ansiedade do teste um desvio padrão de 7,05. Considerando que uma diferença de 5 pontos na média entre os grupos placebo e CBD seja significativa nesta fase, o total recomendado de sujeitos por grupo para é de 24 indivíduos. Foi considerado poder do teste de $80 \%$ e nível de significância de 0,05 para o cálculo.

Para seleção dos voluntários, os seguintes critérios de inclusão foram utilizados:

- DP idiopática;

- ter condições de retornar para reavaliação e dispor de telefone para contato;

- não apresentar alterações cognitivas acentuadas segundo a avaliação clínica;

- não estar em uso de benzodiazepínicos;

- ter condições clínicas para que as doses dos medicamentos antiparkinsonianos sejam mantidas fixas durante todo o estudo;

- estar em uso de doses estáveis de antiparkinsonianos por pelo menos 30 dias antes do início do estudo;

- assinar o TCLE, concordando em participar do estudo. 
Critérios de exclusão foram utilizados:

- Pacientes com parkinsonismo atípico;

- Demência de acordo com os critérios do Manual de Diagnóstico e Estatístico dos Transtornos Mentais ( $5^{\text {a }}$ edição, DSM-5);

- Pacientes com diagnóstico psiquiátrico atual.

\subsection{Procedimentos da pesquisa}

Após a chamada pública, foi realizado o preenchimento de um formulário contento os critérios de seleção para os voluntários interessados. Os interessados que fossem elegíveis foram contatados sequencialmente via telefonema ou e-mail e agendados de acordo com sua disponibilidade para realização de experimentos no Laboratório de Práticas Gerontológicas do departamento de Gerontologia da Universidade Federal de São Carlos.

Dois testes experimentais foram realizados para cada voluntário, com duração de aproximadamente 3 horas cada e intervalo de 15 dias entre eles. Uma avaliação era composta pela coleta de (i) dados demográficos, (ii) avaliação clínica da DP medida pela Unified Parkinson's Disease Rating Scale (UPDRS), Hoehn \& Hahr (H\&Y), Escala de Schwab \& England (S\&E) e Tapping Test, (iii) medidas de ansiedade subjetiva, avaliadas por meio da Escala Analógica Visual de Humor (VAMS) e Escala para e Auto Avaliação ao Falar em Público (SSPS), (iv) medidas de ansiedade avaliada objetivamente, pela mensuração da frequência cardíaca e pressão arterial; (v) tremor captado pelo acelerômetro e (vii) realização do Teste de Simulação de Falar em Público (TSFP).

As avaliações ocorreram antes, durante e após o TSFP. Vale notar que, tanto os participantes quanto pesquisador e foram cegos a respeito da medicação administrada. Os procedimentos adotados no dia do experimento estão descritos na tabela 1. 
Quadro 2- Procedimentos da sessão experimental

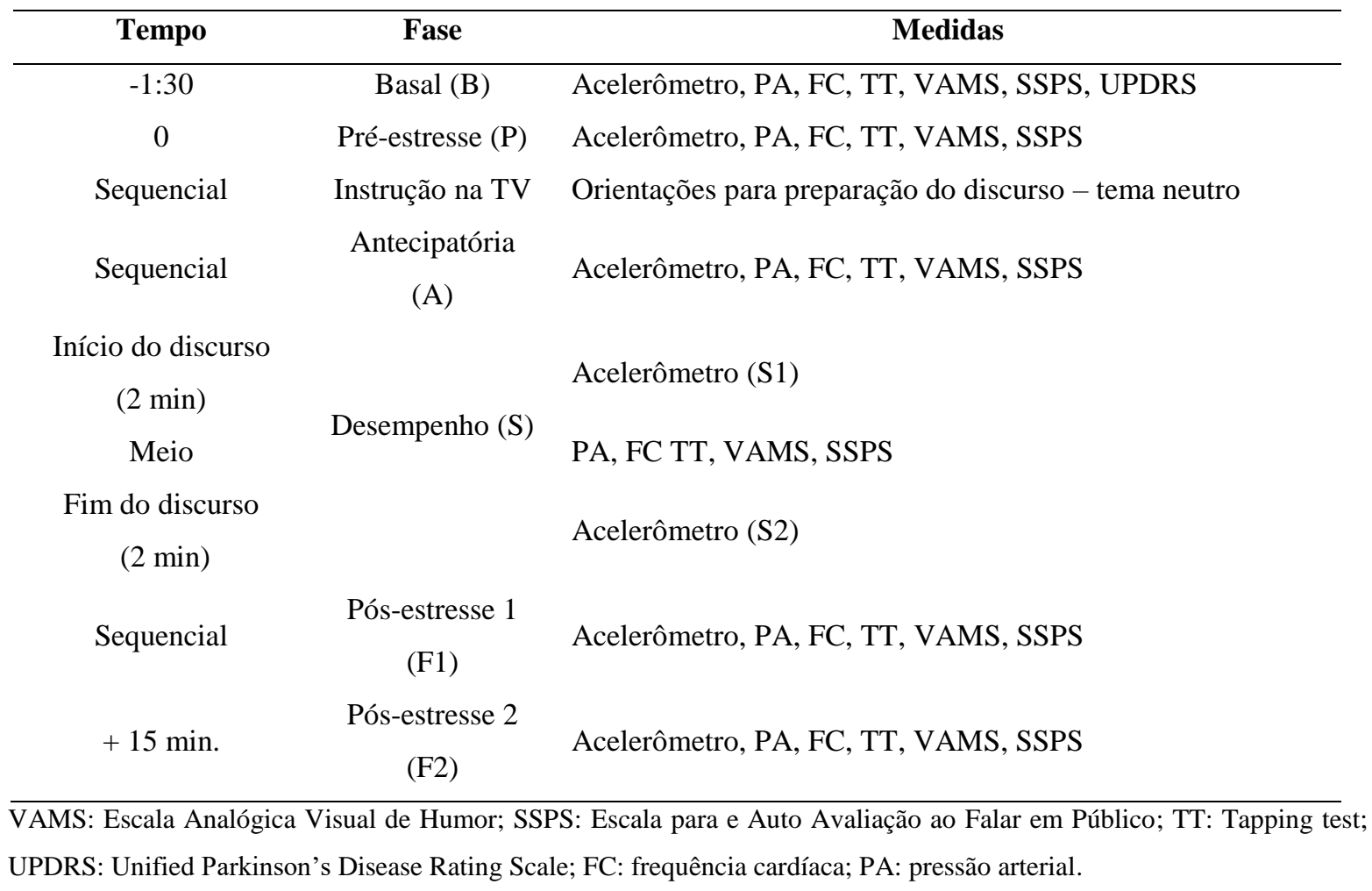

\subsubsection{Preparação do CBD}

As cápsulas de $\mathrm{CBD}$ e placebo foram fornecidas pelo laboratório de Psicofarmacologia do Departamento de Neurociências e Ciências do Comportamento (divisão de Psiquiatria) da Faculdade de Medicina de Ribeirão Preto - USP. A dose de 300 mg de CBD em pó com 99,9\% de pureza produzido pela empresa THC-Pharma (Frankfurt, Alemanha) foi dissolvido em óleo de milho e acondicionado em cápsulas de gelatina que foram preparadas e acondicionadas em frasco escuro. O CBD e o placebo foram fornecidos em cápsulas idênticas.

\subsection{Instrumentos de avaliação}

\subsubsection{Avaliação clínica}

\section{Unified Parkinson's Disease Rating Scale - UPDRS}

A UPDRS é uma escala composta por 42 itens que avalia sintomas, sinais e atividades da vida diária dos pacientes por meio da observação clínica e relato do paciente, sendo que maioria dos itens da escala avalia os sintomas motores dos pacientes. É dividida em quatro 
partes: (parte I) comportamento e humor, (parte II) atividades de vida diária, (III) sintomas motores e (parte IV) complicações (Fahn \& Elton, 1987).

\section{Escala de Hoehn \& Hahr (H\&Y)}

A escala H\&Y foi desenvolvida em 1967 por Melvin Yahrand Margaret Hoehn (Hoehn, Yahr, 1967). Esta escala classifica o indivíduo em um dos cinco estágios de evolução e comprometimento e foi utilizada neste trabalho para avaliação do estágio e gravidade da DP. Neste estudo, utilizamos a classificação modificada, que considera a inclusão de mais dois estágios 1,5 e 2,5. Dessa forma, os estágios são: (1) unilateral, (1,5) envolvimento unilateral e axial, (2) bilateral sem déficit de equilíbrio, (2,5) bilateral leve, com recuperação no "teste do empurrão", (3) bilateral leve a moderada, alguma instabilidade postural, capacidade para viver independente, (4) incapacidade grave, ainda capaz de caminhar ou permanecer de pé sem ajuda e (5) acamado ou cadeirante, a não ser que receba ajuda (Shenkman et al., 2001).

\section{Escala de Schwab \& England (S\&E)}

A escala S\&E foi utilizada para avaliação do grau de independência dos voluntários, para a realização das atividades de vida diária. Ela classifica o nível em porcentagem: (0 \%) acamado, (10\%) totalmente dependente, $(20 \%)$ nada sozinho, $(30 \%)$ com esforço, (40\%) muito dependente, (50\%) mais dependente, (60\%) alguma dependência, (70\%) não completamente independente, $(80 \%)$ totalmente independente e (100\%) completamente independente. Quanto maior a porcentagem, maior a independência (Schwab \& England, 1969).

\section{Tapping Test (TT)}

Neste teste de bradicinesia, solicita-se ao sujeito tocar levemente dois pontos separados por $30 \mathrm{~cm}$ com o dedo indicador. O sujeito deve completar 10 ciclos (um ciclo corresponde tocar os dois lados do segmento), nesse teste avalia-se quanto tempo o voluntário leva para completar os ciclos. O tempo para realizar a tarefa é mensurado tanto para a mão direita quanto a esquerda (Ruiz, Bernardos, Bartolomé, \& Torres, 2007).

\subsubsection{Variáveis e desfechos}


Medidas de ansiedade subjetiva

Escala Analógica Visual de Humor (VAMS)

Esta escala (Norris, 1971) foi traduzida e adaptada para o português (Zuardi \& Karniol, 1981) e é composta por 16 pares de adjetivos com sentidos opostos, separados por uma linha de $10 \mathrm{~cm}$, sobre a qual o sujeito deve assinalar como se sente com relação aos adjetivos no momento específico do preenchimento. Os 16 itens da escala foram agrupados por Norris (1971), em 4 fatores, nesse estudo foram utilizados os fatores agrupados por Zuardi e colaboradores (1993): ansiedade, sedação física, sedação mental e outros sentimentos.

\section{Escala Self-Statements during Public Speaking (SSPS)}

Esta escala inclui itens que estão de acordo com o modelo cognitivo de ansiedade social e consiste de duas sub-escalas (auto avaliação positiva - SSPS-P - e auto avaliação negativa SSPS-N), cada uma composta por cinco itens. É uma escala do tipo likert que o participante pontua de 0 a 5 de acordo com o quanto a afirmação condiz com seu estado subjetivo no momento, com 0 representando a total ausência de concordância com a frase e 5 a total coerência com seus sentimentos (Hofmann \& Dibartolo, 2000; Osório, Crippa, \& Loureiro, 2013).

\section{Medidas de ansiedade objetiva}

Pressão arterial sistêmica (PA) e Frequência Cardíaca $(F C)$

A pressão arterial sistólica e diastólica e a frequência cardíaca foram mensuradas com um esfigmomanômetro digital de pulso automático da marca Omron, modelo HEM-6124, o qual era fixado no pulso esquerdo do voluntário.

\section{Tremores mensurados por sensor de aceleração}

Estudos têm indicado que dados de frequência e amplitude advindos de sensores para captação de aceleração possuem correlações fortes com os tremores mensurados por avaliação clínica (Dai, Zhang, \& Lueth, 2015; Jang et al., 2013; Wile, Ranawaya, \& Kiss, 2014). Neste estudo, foi utilizado o sensor MPU-6050 (InvenSense Inc., San Jose, CA, USA), que tem dimensões pequenas de $4 \mathrm{mmx} 4 \mathrm{mmx} 0,9 \mathrm{~mm}$. O sensor foi conectado a uma placa Arduino Uno R3 que transmitia os dados captados ao computador através de um cabo USB. O sensor foi fixado unilateralmente no dedo indicador da mão que apresenta mais tremores. O sensor em questão gera como saída três sinais, ou séries temporais. Essas séries correspondem à aceleração 
nas três direções espaciais, sendo traduzidas nos eixos $x, y e z$. Neste estudo, foi realizada a fusão entre os eixos baseada na distância euclidiana, gerando uma única série temporal por medida. Essa fusão realiza uma soma dos quadrados, o que permite acessar a aceleração, em cada instante, independente do eixo. De fato, neste estudo, estamos interessados principalmente em medir as amplitudes ao longo de todos os eixos, então a equação que calcula a série temporal utilizada para realizar os experimentos computacionais é: $s(t)=\sqrt{x(t)^{2}+y(t)^{2}+z(t)^{2}}$

Essa fusão independente é importante, pois o sensor pode estar posicionado de diferentes formas ou ser rotacionado durante o teste, gerando cruzamento dos eixos, o que poderia ser interpretado de forma errada pelo programa que realiza a extração dos dados na série temporal. A partir do sinal $s(t)$ foram realizadas todas as análises de tempo-frequência. Por se tratarem de séries temporais, foram utilizadas ferramentas capazes de extrair informação das amplitudes de $s(t)$ ao longo do tempo.

Todas as técnicas receberam como entrada o sinal $s(t)$ e produziram como saída uma visualização diferente ou um novo sinal transformado, no qual ficaram mais evidentes certas características difíceis de observar no sinal original. Mais do que simplesmente utilizar um algoritmo que produz saídas, a investigação focou em encontrar padrões nos dados que possibilite avaliar o tremor utilizando unicamente os dados de aceleração.

A fim de encontrar esses padrões para toda a série, empregamos uma análise de frequência usando o algoritmo de Transformação Rápida de Fourier. Devido aos limites teóricos para as observações de amostragem ao longo do tempo, os sinais foram filtrados para a frequência de $32 \mathrm{~Hz}$ para evitar interpretações erradas da análise (Gibson, 1994). As seguintes variáveis foram extraídas do sinal: a entropia do espectro de potência (PSE) é uma medida da complexidade da informação computada ao longo de todas as amplitudes de frequiência; a frequência de pico do espectro de potência (PSPF) diz respeito às frequências principais (em termos de ciclos por segundo - Hz) que representam o tremor; e o pico do espectro de potência (PSP) codifica as amplitudes das freqüências fundamentais do movimento. As características foram computadas conforme descrito por Ponti et al. (2017).

\subsection{Teste de Simulação de Falar em Público (TSFP)}

O teste de simulação de falar em público (TSFP) é um modelo experimental utilizado para induzir ansiedade. Pede-se ao sujeito que elabore um discurso sobre um tema neutro que será supostamente gravado e avaliado por um psicólogo. Durante o discurso, o voluntário permanece sentado em frente a um aparelho de televisão que mostra a sua própria imagem, captada através de uma câmera posicionada acima da tela (McNair et al., 1982). Neste estudo, 
foi solicitado que o voluntário falasse um discurso sobre o sistema de transportes de sua cidade no primeiro experimento e sobre o sistema de abastecimento água e esgoto no segundo experimento, numa tentativa de minimizar os efeitos de aprendizagem entre os dois experimentos.

\subsection{Análise estatística}

A análise descritiva dos dados demográficos e clínicos foi realizada apontando a frequência percentual e média. As diferenças entre os escores dos fatores da VAMS, SSPS, PA, FC e características do acelerômetro foram verificadas por análise da variância (ANOVA) de medidas repetidas, analisando-se os fatores fases, droga, ordem e interação entre elas. Nos casos que a condição de esfericidade foi violada, os graus de liberdade foram corrigidos com teste de Greenhouse-Geisser. Para normalização nos dados (sinais) do acelerômetro, foi utilizado z-score, de forma que os sinais tenham média 0 e desvio padrão próximo a 1 .Os dados foram analisados usando o programa SPSS-21 e o nível de significância adotado será p<0,05. 
RESULTADOS 


\section{RESULTADOS}

Dos 179 questionários respondidos, 24 voluntários elegíveis foram selecionados sequencialmente de acordo com os critérios de seleção. Após, um sorteio foi realizado entre os 24 selecionados para receber $\mathrm{CBD}$ ou placebo no primeiro experimento. Um voluntário foi excluído por não completar as escalas, dessa forma, 11 participantes foram incluídos no grupo placebo e 12 no grupo no CBD para análise. Os resultados clínico-demográficos, ansiedade subjetiva e fisiológica são apresentados a seguir:

\section{1 Dados clínico-demográficos}

Em relação às características demográficas da amostra, a maioria dos participantes era do sexo masculino ( $n=22)$, casados $(n=22)$ e aposentados $(n=19)$. A média de idade foi de $64,13$ anos $( \pm 9,72)$ com 12,79 anos de escolaridade $( \pm 6,46)$ (Tabela 1$)$.

Tabela 1- Dados clínico-demográficos em pacientes com DP, Ribeirão Preto-SP, 2018.

\begin{tabular}{|c|c|c|}
\hline \multicolumn{2}{|c|}{ Variáveis } & \multirow{2}{*}{$\begin{array}{c}\begin{array}{c}\text { Voluntários } \\
(\mathbf{N}=\mathbf{2 4})\end{array} \\
22(91,7 \%)\end{array}$} \\
\hline Sexo & Masculino N (\%) & \\
\hline & Feminino $\mathrm{N}(\%)$ & $2(8,3 \%)$ \\
\hline \multirow[t]{3}{*}{ Idade } & $\mathrm{x}(\sigma)$ & $64,1( \pm 9,72)$ \\
\hline & Solteiro & $0(0 \%)$ \\
\hline & Divorciado & $0(0 \%)$ \\
\hline \multirow[t]{2}{*}{ Estado Civil } & Viúvo & $2(8,3 \%)$ \\
\hline & Casado & $22(91,7 \%)$ \\
\hline \multirow[t]{2}{*}{ Escolaridade } & $\mathrm{x}(\sigma)$ & $12,8( \pm 6,46)$ \\
\hline & Autônomo N (\%) & $5(20,8 \%)$ \\
\hline \multirow[t]{2}{*}{ Profissão } & Empregado N (\%) & $19(79,2 \%)$ \\
\hline & Do lar N (\%) & $0(0 \%)$ \\
\hline Aposentado N (\%) & & $19(79,2 \%)$ \\
\hline
\end{tabular}

$\mathrm{x} \mid \sigma:$ média|desvio padrão, $\mathrm{N}$ : frequência absoluta, \%: frequência relativa.

Em relação aos dados clínicos, todos os pacientes relataram início dos sintomas após os 50 anos de idade com duração média de 6,5 anos $( \pm 5,03)$. Todos os participantes foram classificados entre o estágio 1 e 2,5, segundo a escala de Hoehn \& Yahr. A escala funcional de Schwab \& England variou entre 70 e 90\%, com média de 85\% ( $\pm 7,79 \%)$. Em relação à parte motora da UPDRS, a média foi $21,71( \pm 9,38)$ (Tabela 2$)$. A maioria dos pacientes estava 
em uso de levodopa $(n=19)$. As outras medicações em uso foram pramipexol $(n=11)$, amantadina $(n=8)$, selegilina $(n=3)$, biperideno $(n=2)$, e entacapona $(n=1)$.

Tabela 2- Características clínicas da amostra estudada, Ribeirão Preto-SP, 2018.

\begin{tabular}{|c|c|c|}
\hline \multicolumn{2}{|c|}{ Variáveis } & \multirow{2}{*}{$\begin{array}{c}\text { Voluntários }(\mathbf{n}=\mathbf{2 4}) \\
0(0 \%)\end{array}$} \\
\hline & Início Precoce $(<50$ anos $)$ & \\
\hline Idade de início da DP & Início Tardio ( $\geq 50$ anos) & $24(100 \%)$ \\
\hline \multirow[t]{5}{*}{ Duração DP } & Média $(\sigma)$ & $6,48( \pm 5,03)$ \\
\hline & $\mathrm{H} \& \mathrm{Y} 1-\mathrm{N}(\%)$ & $7(29,17 \%)$ \\
\hline & $\mathrm{H} \& \mathrm{Y} 1,5-\mathrm{N}(\%)$ & $2(8,33 \%)$ \\
\hline & $\mathrm{H} \& \mathrm{Y} 2-\mathrm{N}(\%)$ & $14(58,33 \%)$ \\
\hline & $\mathrm{H} \& \mathrm{Y} 2,5-\mathrm{N}(\%)$ & $1(4,17 \%)$ \\
\hline Gravidade da DP & $\mathrm{H} \& \mathrm{Y} 3-\mathrm{N}(\%)$ & $0(0 \%)$ \\
\hline \multirow[t]{3}{*}{ (Hoehn \& Hahn) } & $\mathrm{H} \& \mathrm{Y} 4-\mathrm{N}(\%)$ & $0(0 \%)$ \\
\hline & $\mathrm{H} \& \mathrm{Y} 5-\mathrm{N}(\%)$ & $0(0 \%)$ \\
\hline & UPDRS I $(\mathrm{x} \mid \sigma)$ & $2,21( \pm 1,74)$ \\
\hline \multirow[t]{3}{*}{ UPDRS } & UPDRS II $(\mathrm{x} \mid \sigma)$ & $12,71( \pm 5,47)$ \\
\hline & UPDRS III $(\mathrm{x} \mid \sigma)$ & $21,71( \pm 9,38)$ \\
\hline & UPDRS IV $(\mathrm{x} \mid \sigma)$ & $4,75( \pm 3,66)$ \\
\hline$S \& E$ & $\mathrm{x}(\sigma)$ & $85( \pm 7,79)$ \\
\hline \multicolumn{3}{|c|}{ Outras patologias clínicas } \\
\hline & $\operatorname{Sim} N(\%)$ & $14(58,3 \%)$ \\
\hline & Não N (\%) & $10(41,7 \%)$ \\
\hline
\end{tabular}

$\overline{\mathrm{x} \mid \sigma: \text { média|desviopadrão, H\&Y: Escala de Hoehn - Yahr, UPDRS: Unified Parkinson's Disease Rating }}$ Scale, S\&E: Escala de Schwab \& England.

\subsection{Medidas de sintomas de ansiedade subjetiva}

VAMS

Fator ansiedade

A ANOVA de medidas repetidas demonstrou um efeito significativo para o fator ansiedade da VAMS para droga $(F=6,27 ; p=0,021)$ e fase $(F=5,26 ; p=0,004)$, sem efeito de ordem e para interação entre os fatores (figura 2). 


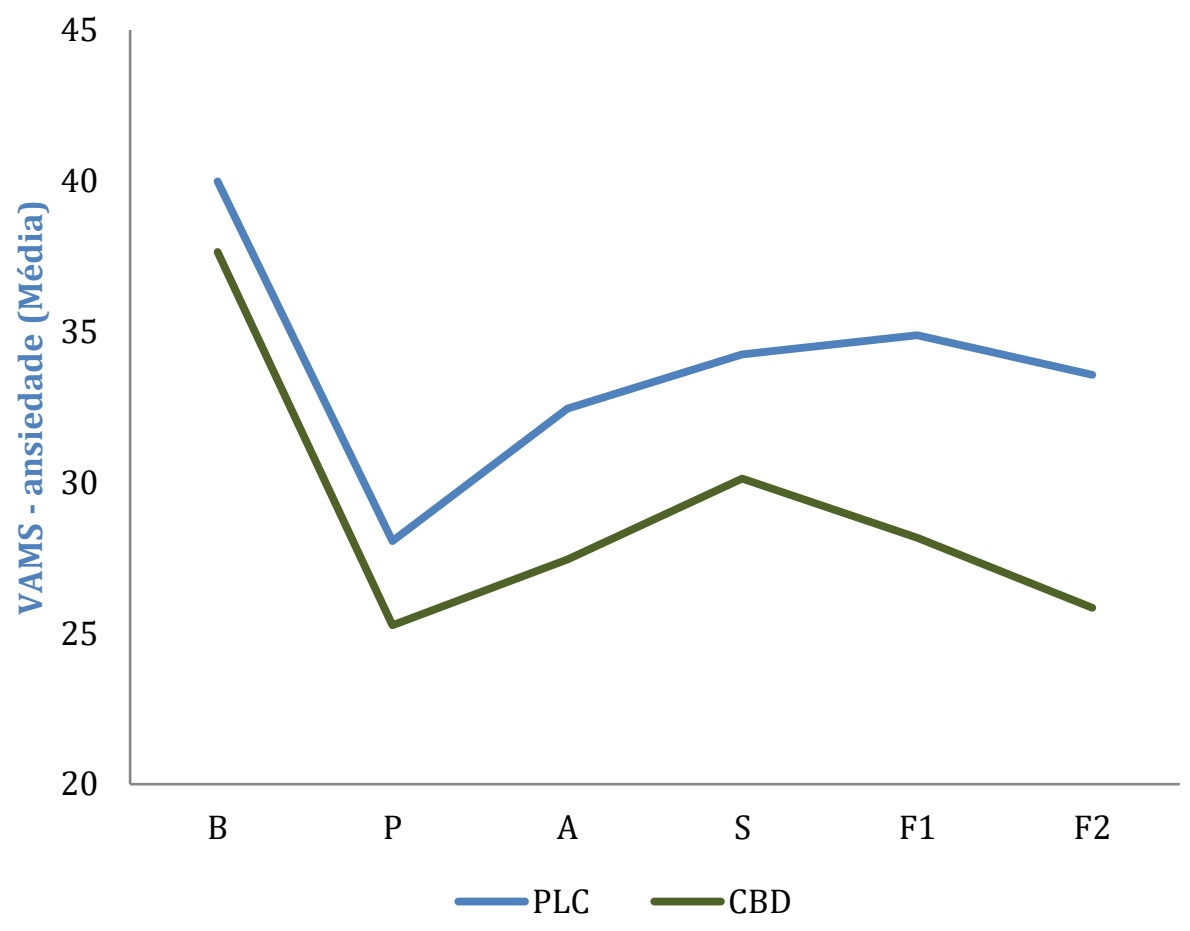

Figura 2- Comparação da administração CBD X PCB para o fator ansiedade da VAMS

PLC: Placebo, CBD: Canabidiol, B: basal, P: pré-estresse, A: antecipatória, S: desempenho, F1: pós-estresse 1, F2: pós-estresse 2.

Fator sedação mental

Em relação ao fator sedação mental, não houve diferenças em relação à droga ( $\mathrm{F}=0,750$; $\mathrm{p}=0,396)$, com efeito apenas de fase $(\mathrm{F}=5,784 ; \mathrm{p}=0,002)$ (figura 3$)$. 


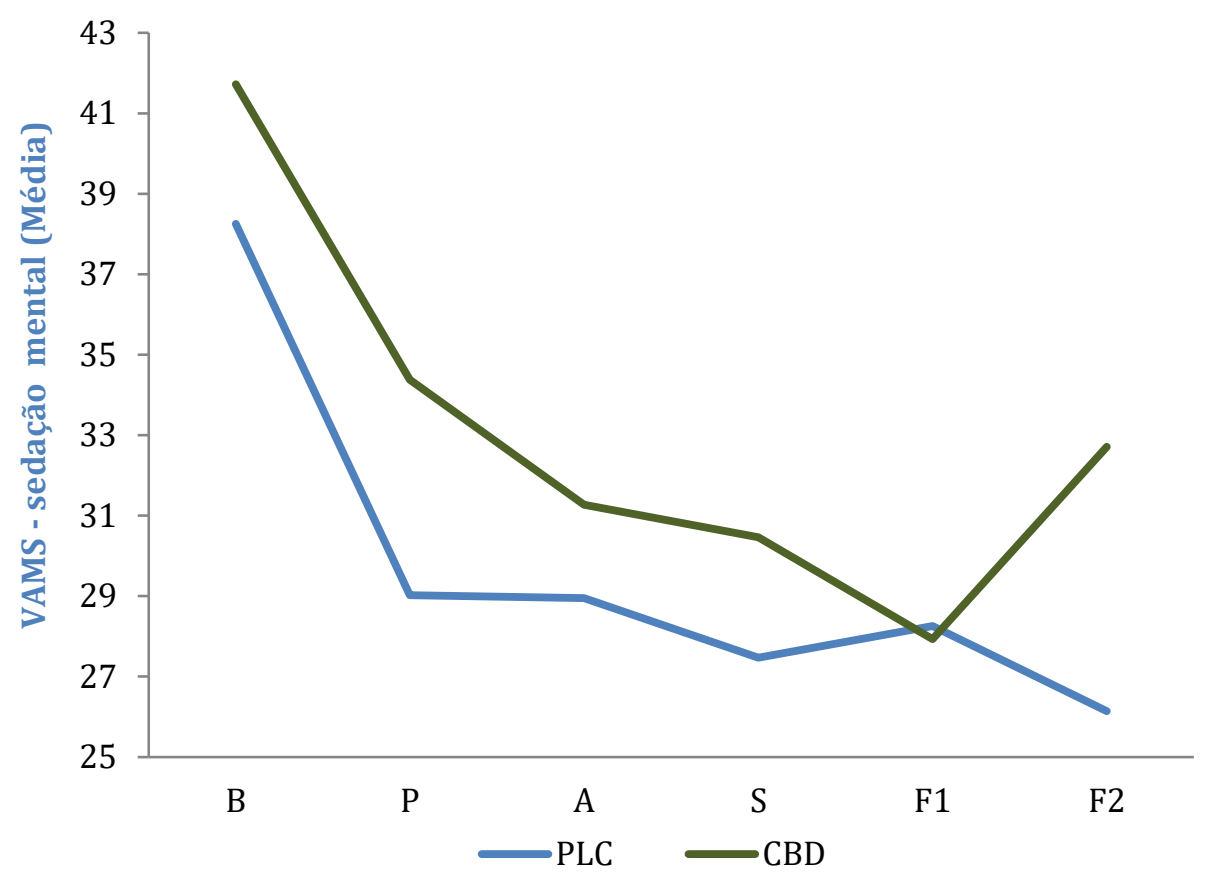

Figura 3- Comparação da administração CBD X PCB para o fator sedação mental da VAMS.

PLC: Placebo, CBD: Canabidiol, B: basal, P: pré estresse , A: antecipatória, S: desempenho,

F1: pós estresse 1, F2: pós estresse 2 .

\section{Fator sedação física}

Da mesma forma, não houve diferenças em relação à droga $(\mathrm{F}=2,647 ; \mathrm{p}=0119)$ para o fator sedação física, com efeito apenas de fase $(\mathrm{F}=4,677 ; \mathrm{p}=0,016)$ (Figura 4). Em relação ao fator outros sentimentos, não foram encontrados efeitos em nenhum dos fatores. 


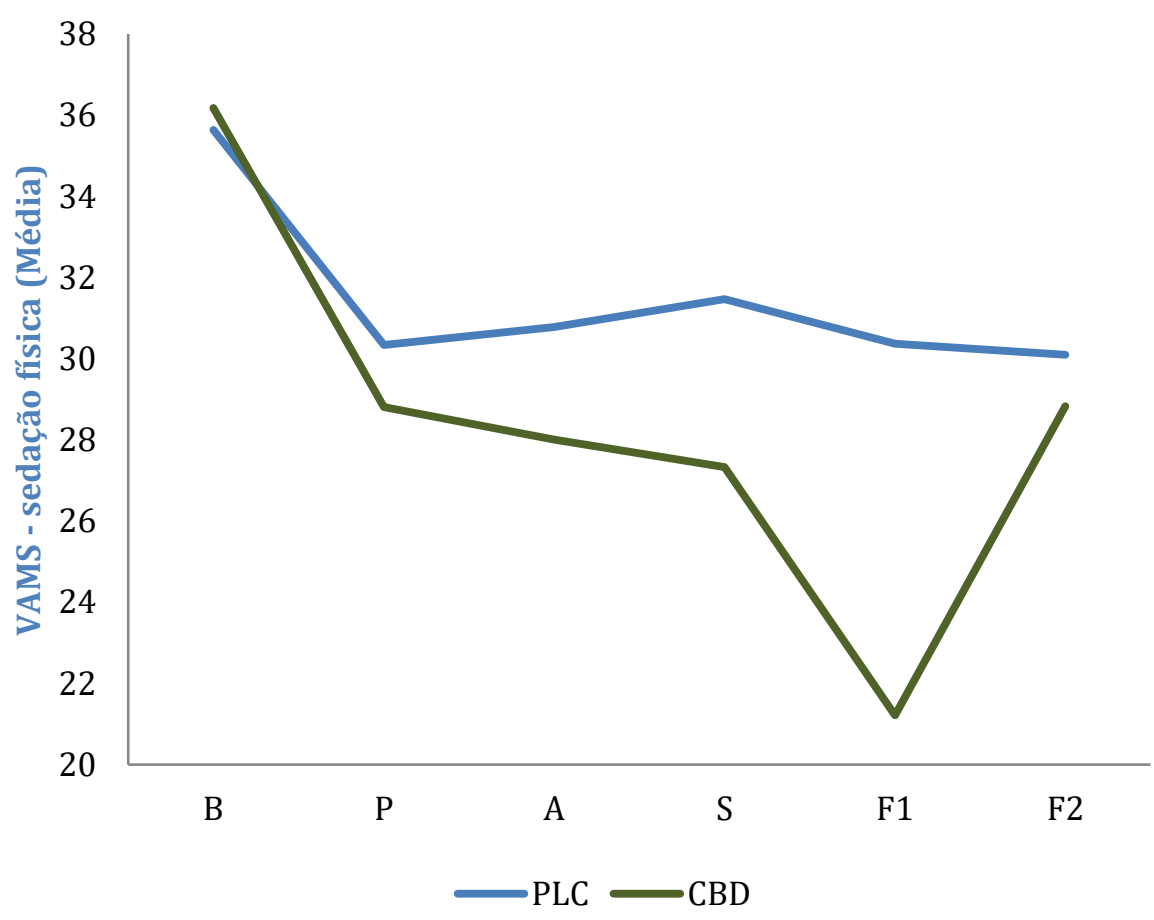

Figura 4- Comparação da administração CBD X PCB para o fator sedação física da VAMS. PLC: Placebo, CBD: Canabidiol, B: basal, P: pré estresse , A: antecipatória , S: desempenho, F1: pós estresse $1, \mathrm{~F} 2$ : pós estresse 2 .

\section{SSPS}

As medidas da ANOVA mostraram que não houve diferença nas questões positivas do SSPS, com relação ao efeito de droga $(F=1,494 ; p=0,235)$ e fase $(F=0,489 ; p=0,615)$. Do mesmo modo, não houve diferença para questões negativas do SSPS para droga $(\mathrm{F}=0,222$; $\mathrm{p}=0,643)$ e fase $(\mathrm{F}=1,596 ; \mathrm{p}=0,203)$.

\subsection{Medidas de ansiedade fisiológica}

Frequência cardíaca

A ANOVA de medidas repetidas demonstrou um efeito significativo para a FC para fase $(F=6,066 ; p=0,004)$, sem efeito de droga, ordem e para interação entre os fatores (figura 5). 


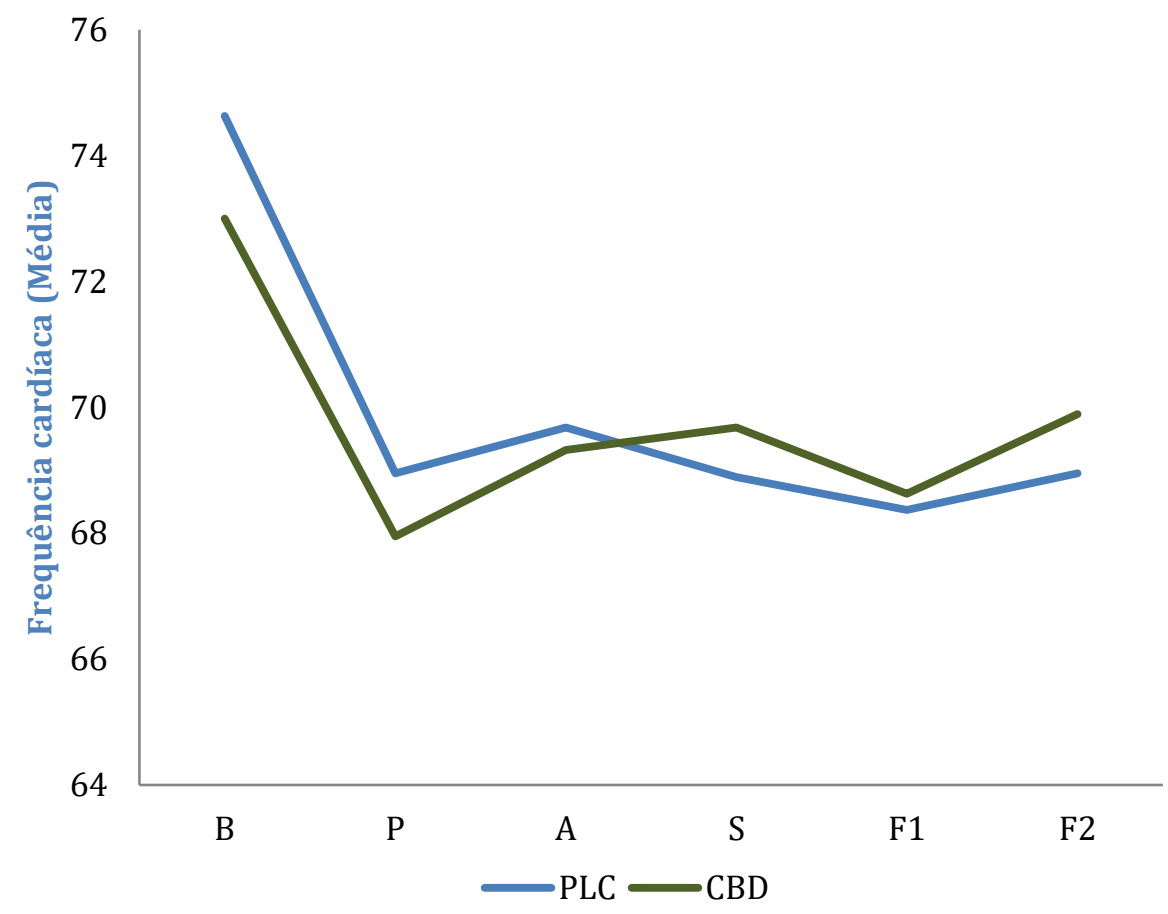

Figura 5- Comparação da administração CBD X PCB para a frequência cardíaca.

PLC: Placebo, CBD: Canabidiol, B: basal, P: pré estresse , A: antecipatória , S: desempenho, F1: pós estresse 1, F2: pós estresse 2.

Pressão arterial sistêmica

As medidas da ANOVA para a pressão arterial sistólica demonstraram que não houve diferença para nenhum dos fatores, em relação ao efeito droga $(F=2,468 ; p=0,135)$, fase $(F=$ $0,973 ; p=0,405)$ e para interação entre os fatores $(F=0,197 ; p=0,910)$.

Do mesmo modo, para a pressão arterial diastólica, não foi verificada diferença significativa para droga $(\mathrm{F}=0,079 ; \mathrm{p}=0,782)$, fase $(\mathrm{F}=1,703 ; \mathrm{p}=0,185)$ e interação entre os fatores $(\mathrm{F}=1,182 ; \mathrm{p}=0,324)$.

\subsection{Medidas de tremores e bradicinesia}

Em relação às variáveis captadas pelo acelerômetro, a ANOVA de medidas repetidas mostrou diferenças significativas para droga apenas na variável PSP $(F=6,19 ; p=0,022)$. Não houve diferenças significativas nas variáveis PSE ( $F=1,63 ; p=0,216)$ e PSPF $(F=0,02 ; p=0,899)$ para droga. Assim como, não houve diferenças para fase ou interação droga por fase em todas 
as variáveis captadas pelo sensor de aceleração. Dois participantes não tiveram as variáveis avaliadas, pois a captação do sinal não foi adequada. A figura 6 mostra os valores da PSP ao longo do TSFP.

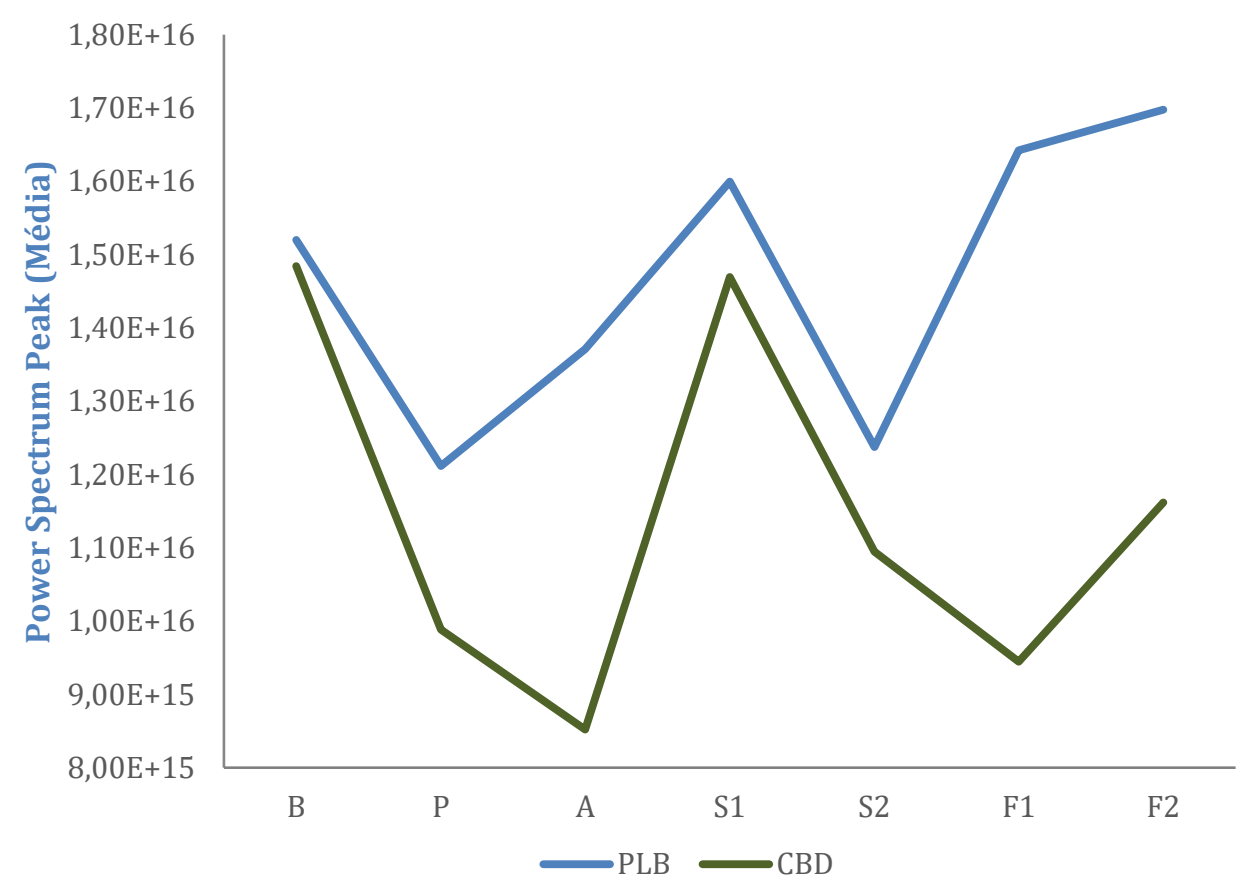

Figura 6- Comparação da administração CBD X PCB para característica PSP.

PLC: Placebo, CBD: Canabidiol, B: basal, P: pré estresse, A: antecipatória, S: desempenho, F1: pós estresse 1, F2: pós estresse 2.

Em relação ao TT para avaliação de bradicinesia, não foi observado efeito para droga $(\mathrm{F}=0,15 ; \mathrm{p}=0,701)$. Houve diferenças significativas para fase $(\mathrm{F}=10,22 ; \mathrm{p}<0,001)$ e interação droga por ordem $(\mathrm{F}=4,39 ; \mathrm{p}=0,049)$, de modo que o tempo gasto no TT era menor ao longo do TSFP e menor na segunda sessão experimental, o que é esperado após a repetição de testes de bradicinesia. 


\section{DISCUSSÃO}




\section{DISCUSSÃO}

Nossos achados mostram que a administração aguda do CBD tem efeito sobre a ansiedade experimentalmente induzida pelo TSFP como também sobre a amplitude do tremor durante o teste, utilizando a dose de $300 \mathrm{mg}$ em pessoas com DP. Nessa linha, estudos têm apresentado evidências do efeito ansiolítico do CBD sobre a ansiedade tanto em modelo animal quanto humano (Blessing, Steenkamp, Manzanares \& Marmar, 2015). Do mesmo modo, estudos clínicos têm demonstrado que a administração oral do CBD, utilizando doses que variam de 100 à $900 \mathrm{mg}$ são capazes de exercer efeito ansiolítico em humanos (Karniol, Shirakawa, Kasinski, Pfeferman \& Carlini, 1974; Zuardi, Shirakawa, Finkelfarb \& Karniol, 1982; Zuardi, Cosme, Graeff \& Guimarães,1993; Crippa et al, 2014; Bhattacharyya et al., 2010; Crippa et al, 2011; Bergamaschi et al, 2011; Martin-Santos et al, 2012; Das et al., 2013; Hindocha et al, 2015; Zuardi et al, 2017). Ainda, os efeitos ansiolíticos do CBD também foram encontrados em estudos que utilizaram o TSFP como modelo experimental de ansiedade mais especificadamente em voluntários saudáveis (Zuardi et al., 1993) e com ansiedade social (Bergamaschi et al., 2011).

Este efeito pode ser justificado, já que o $\mathrm{CBD}$ atua em regiões cerebrais relacionadas à ansiedade. Fusar-Poli et al. (2009) realizaram um estudo de neuroimagem em sujeitos saudáveis e mostraram que o CBD reduz a efetividade da conexão entre o córtex cingulado anterior e a amígdala durante o processamento de estímulos com expressões faciais de medo (Fusar-Poli et al., 2009). A amígdala é uma estrutura diretamente relacionada ao medo condicionado e com o comportamento de luta e fuga (Duvarci \& Pare, 2014) e já foi implicada com a ansiedade em pacientes com DP (Vriend et al., 2016). A redução volumétrica da amígdala esquerda parece estar relacionada com mais sintomas de ansiedade em pacientes com DP (Vriend et al., 2016). Este fato sugere que o CBD possa ser uma alternativa em pacientes com DP e ansiedade

Estudos têm apontado para aspectos neurobiológicos que poderiam justificar esse efeito ansiolítico (de Mello Schier et al., 2014). O CBD apresenta múltiplas ações farmacológicas, atuando em diversos neuroreceptores como o CB1, CB2, TRPV1 e 5-HT $1 \mathrm{~A}$ (Campos, et al., 2012). Uma das hipóteses é que o CBD atue antagonizando os agonistas dos receptores CB1 (Thomas et al., 2007). Além disso, como mencionado, especulações em relação às estruturas cerebrais relacionadas com a ansiedade sugerem que a amígdala é responsável pelo controle da ansiedade e medo. Sabe-se e que receptores CB1 estão expressos em grande quantidade nessa região cerebral (Herkenham et al., 1990; Glass, Dragunow, Faull, 1997; Katona et al., 2001). 
Outra possibilidade seria que o CBD atue como um agonista direto do 5-HT $1 \mathrm{~A}$ aumentando a disponibilidade de serotonina na fenda sináptica (Russo, Burnett, Hall, Parker, 2005; Campos, Guimarães, 2008; Gomes, Resstel, \& Guimarães, 2011; Noreen, Muhammad, Akhtar, Azam \& Anwar, 2018). Em um estudo com modelo animal da DP, foi observada diminuição da densidade dos neurônicos serotoninérgicos no núcleo dorsal da rafe e da expressão de receptores 5-HT 1 A na região pré-limbica do córtex pré-frontal ventromedial, a qual poderia ser responsável pelo aumento das respostas ansiogênica (Hui et al., 2015). Paralelamente, a administração do 8-OH-DPAT, um agonista do receptor 5-HT $1 \mathrm{~A}$, no córtex pré-frontal ventromedial (Hui et al., 2015) e na amígdala (Sun et al., 2015) apresenta ação ansiolítica em modelos da DP em ratos.

Além disso, estudos em humanos reafirmam essa hipótese, sugerindo que o CBD tem efeito sobre algumas estruturas cerebrais relacionadas ao controle da ansiedade e medo. Como é o caso do estudo de Crippa e colaboradores (2004), que propuseram investigar o efeito do CBD sobre o fluxo cerebral em uma amostra de indivíduos saudáveis na dose de $400 \mathrm{mg}$. Os resultados desse estudo mostraram que o CBD atua sobre regiões límbicas e infralímbicas, aumentando a atividade no giro hipocampal esquerdo e diminuindo as do complexo amígdalahipocampo esquerdo, atividades as quais condizem com um efeito ansiolítico (Crippa et al., 2004). Outro estudo do mesmo autor buscou identificar as bases neurais relacionadas aos efeitos ansiolíticos do CBD com uma amostra de pessoas com Transtorno de Ansiedade Social com uma dose de $400 \mathrm{mg}$. Foram verificados efeitos ansiolíticos nas mesmas regiões cerebrais descritas no estudo anterior (Crippa et al., 2011). Ainda num outro estudo, utilizando a ressonância magnética funcional, com a dose de $600 \mathrm{mg}$ e, da mesma forma, investigando as correlações neurais dos efeitos ansiolíticos, obteve-se uma atenuação do envolvimento do córtex cingulado e amígdala perante uma situação de estimulação ao medo, sugerindo um efeito ansiolítico em indivíduos saudáveis (Fusar-Poli et al., 2009). Também, é interessante notar que Zuardi e colaboradores (1993) utilizaram a ipsapirone, um agonista parcial do receptor 5-HT $1 \mathrm{~A}$, em voluntários saudáveis, a qual atenuou os sintomas de ansiedade induzidos pelo TSFP. Esse mecanismo de ação pode ser aventado em relação aos efeitos ansiolíticos encontrados no nosso estudo.

Uma meta-análise recente apontou que $31 \%$ dos pacientes com DP apresentam transtornos de ansiedade (Broen et al., 2016). Além disso, sintomas de ansiedade clinicamente relevantes estão comumente presentes mesmo na ausência de um transtorno de ansiedade específico e podem estar associados à gravidade dos sintomas motores, flutuações motoras e duração da doença (Chagas et al., 2009; Sagna, Gallo, \& Pontone, 2014). Apesar disso, poucos estudos 
foram realizados para avaliar o tratamento da ansiedade em pacientes com DP. As opções terapêuticas disponíveis são inibidores seletivos da receptação de serotonina e benzodiazepínicos, os quais geralmente acarretam efeitos colaterais como aumento dos tremores, aumento do risco de quedas e piora da cognição (Pontone et al., 2013), especialmente em idosos. Estes pontos reforçam a necessidade de viabilizar alternativas para o tratamento dos sintomas de ansiedade na DP, e CBD poderia ser uma possibilidade, considerado que esta substância tem-se mostrado segura e com poucos efeitos colaterais (Bergamaschi, et al., 2011).

Quanto aos efeitos colaterais, alguns estudos já têm apontado para a segurança no uso do CBD para fins terapêuticos, considerando inclusive altas doses (Pisanti et al., 2017). Com esse perfil, estudos utilizando doses de até $1.500 \mathrm{mg} /$ dia com administração aguda e crônica em humanos têm mostrado que a droga tem sido bem tolerada em humanos (Bergamaschi et al., 2011; Iffland \& Grotenhermen, 2017). Isso também foi verificado no presente estudo, já que os voluntários não relataram efeitos colaterais durante as avaliações. A maioria dos estudos encontrados na literatura que fazem a administração do CBD refere-se ao tratamento de transtornos psicóticos e epilepsia. Nesses casos, são verificados apenas efeitos discretos como sonolência (Iffland \& Grotenhermen, 2017). No caso dos efeitos colaterais em pessoas com DP, um importante estudo foi realizado por Zuardi e colaboradores (2009), a fim de verificar a eficácia, tolerabilidade e segurança do CBD em pacientes com DP, nessa pesquisa, seis pacientes foram avaliados durante quatro semanas e houve administração da dose de 150 $\mathrm{mg} / \mathrm{dia}$. Os resultados mostraram que o CBD teve efeito sobre os sintomas motores, diminuindo as pontuações da UPDRS, além de não afetar a função cognitiva, não foram verificados efeitos adversos durante o estudo (Zuardi et al., 2009). Estes dados empíricos reafirmam os estudos realizados ao longo dos anos, que têm apontado para o CBD como uma substância sem efeitos psicoativos, alucinógenos e tóxicos, diferentemente de outros componentes da Cannabis como o THC (Zuardi et al., 2008).

Quanto à avaliação de medidas objetivas da ansiedade como a PA e FC, não foi verificado efeito significativo do CBD sobre essas medidas. Desfecho similar também é encontrado na literatura, utilizando diferentes amostras, dosagens e desenhos de estudo (Sultan, Millar, England, \& O'Sullivan, 2017). Quanto aos estudos realizados em humanos, desde a década de 70, alguns estudos já vinham sendo realizados em amostras de indivíduos saudáveis (Belgrave et al, 1979, Gong, Tashkin, Simmons, Calvarese, \& Shapiro, 1984). Um destes estudos, realizado por Gong e colaboradores (1984), usando uma alta dosagem de $1200 \mathrm{mg}$. não encontrou mudança significativa na pressão arterial e FC (Gong, Tashkin, Simmons, Calvarese, \& Shapiro, 1984). 
Estudos mais recentes também têm mostrado resultados semelhantes. Estudos com efeito agudo não apresentaram mudança na FC (Belgrave et al, 1979; Zuardi et al., 1993; Martin-Santos et al., 2012); pressão arterial sistólica (Gong, Tashkin, Simmons, Calvarese, \& Shapiro, 1984; Zuardi et al., 1993) e pressão arterial diastólica (Gong, Tashkin, Simmons, Calvarese, \& Shapiro, 1984). Da mesma forma, alguns estudos com administração crônica de CBD em humanos não apresentam efeito significativo na FC (Consroe et al., 1991) e pressão arterial sistêmica (Gong et al, 1984). Apenas num recente estudo em humanos utilizando um modelo de estresse induzido, foi verificado um efeito do CBD sobre a pressão arterial sistêmica de repouso, reduzindo esta medida antes e depois do teste e aumentando a FC significativamente em indivíduos saudáveis (Jadoon, Tan \& O’Sullivan, 2017).

Além disso, os resultados deste estudo sugerem que o CBD atenuou a ansiedade induzida pelo TSFP e que houve uma redução da amplitude dos tremores mensurados pelo acelerômetro. É provável que o aumento de ansiedade acarrete o aumento da amplitude dos tremores, considerando que a presença de tremores pode ocorrer mesmo em sujeito saudáveis em situações de ansiedade. Porém, nossos resultados não nos permitem afirmar que o CBD atenuou o tremor concomitantemente à ansiedade. A relação entre ansiedade e os sintomas motores tem sido amplamente estudada, mostrando que alguns sintomas motores têm aumentado na presença de ansiedade (Salazar, Neargarder \& Cronin-Golomb, 2017; Chagas et al., 2017). O estudo de Broen e colaboradores (2016) confirma essa ideia, mostrando uma correlação entre o aumento da ansiedade e sintomas motores e presença de flutuações motoras, por exemplo, em pacientes com DP (Broen et al., 2016). Ainda, um estudo realizado por Chagas e colaboradores (2017) mostrou que os tremores na DP podem aumentar em situações que geram ansiedade (Chagas et al., 2017). Somado a isto, a presença e gravidade dos tremores pode retroalimentar os sintomas de ansiedade pela avaliação negativa do próprio indivíduo, conforme é observado na ansiedade social que é mais prevalente na DP (Moriyama et al., 2016). Diante disso, nesse estudo, é possível que o efeito do CBD sobre o tremor esteja relacionado à diminuição de sintomas de ansiedade.

Outra hipótese que justificaria o efeito do CBD sobre o sintoma motor, seria a ação da droga diretamente sobre o sintoma, já que o CBD poderia influenciar algumas estruturas cerebrais relacionadas ao controle motor (Fernández-Ruiz, Gonzalez, 2005). Nessa linha, há indícios de que o receptor CB1 esteja expresso em alto nível no gânglio basal e cerebelo (Herkenham et al., 1990; Herkenham, Lynn, de Costa, \& Richfield , 1991b), estruturas cerebrais responsáveis pela coordenação do controle motor (Groenewegen, 2003), localizados predominantemente nos terminais pré-sinápticos (Svíženská, Dubový, \& Šulcová, 2008). 
Entretanto, a expressão dos receptores CB1 pode ser diferente ao longo da DP, com downregulation nas fases inciais da doença e upregulation nas fases tardias (García-Arencibia et al., 2009). Esse aspecto é importante, pois o CBD poderia levar a respostas diferentes em relação aos sintomas motores. Além disso, o CBD apresenta amplo espectro de ação, e suas funções de antagonizar a ação de agonistas CB1 e inibir a enzima FAAH, levando ao aumento de anandamida, um agonista CB1, são fundamentais para entender seu papel na função motora (Peres et al., 2018). Desta forma, estes aspectos devem ser considerados em pesquisas futuras com o CBD e podem explicar em parte os resultados inconsistentes encontrados nos estudos de canabinóides e sintomas motores da DP (Arjmand et al., 2015).

O receptor 5HT-1A também tem papel importante na regulação dos sintomas motores e está presente em diversas regiões cerebrais relacionadas ao controle motor (Ohno, 2011; Huot \& Fox, 2013), sendo que a gravidade do tremor parece estar relacionada com a redução deste receptor (Doder et al., 2003). Desta forma, devemos aventar a possibilidade da atuação do CBD neste receptor ocasionar a redução da amplitude dos tremores. Estes dados podem ser suportados por um estudo que apontou que a mirtazapina, que apresenta efeito agonista no receptor 5-HT $1 \mathrm{~A}$, poderia diminui o tremor parkinsoniano (Gordon et al., 2002). Confirmando isso, um estudo em modelo animal, com o objetivo de verificar o efeito motor do CBD mediado pelo receptor 5-HT $\mathrm{H}_{1 \mathrm{~A}}$, encontrou que o CBD em doses superiores que $10 \mathrm{mg}$, pode influenciar a atividade motora, com destaque para atividade vertical (Espejo-Porras, Fernández-Ruiz, Pertwee, Mechoulam, \& García, 2013).

Como limitação deste estudo, inserimos a administração do CBD em uma única dose, ao passo que um estudo com administração crônica, poderia agir progressivamente sobre medidas objetivas e subjetivas de ansiedade, permitindo acompanhar a eficácia do tratamento ao longo do tempo. Por outro lado, um importante avanço encontrado em nosso estudo foi a utilização de medidas objetivas para verificação do tremor em pessoas com DP, medida até então, não encontrada na literatura para esse desfecho e público específico. Os resultados encontrados neste estudo estão alinhados com o que sugere a literatura. No entanto, a maioria dos estudos encontrados na literatura foi realizada com amostras de voluntários saudáveis e não foram encontrados estudos que verificassem o efeito do CBD na ansiedade induzida em pessoas com DP, considerando as peculiaridades de doença. 


\section{CONCLUSÃO}

A prevalência elevada de sintomas de ansiedade em pessoas com DP, somada ao agravamento dos sintomas motores e consequente impacto sobre a $\mathrm{QV}$, aponta para a necessidade de tratamentos que atuam nestes sintomas de modo eficaz e com menos efeitos colaterais. Nesse estudo, nossos resultados mostram que:

$\checkmark$ O CBD tem efeito sobre os sintomas de ansiedade subjetiva no fator ansiedade da VAMS na dose de $300 \mathrm{mg}$ num modelo de ansiedade experimentalmente induzida em pessoas com DP;

$\checkmark \mathrm{O}$ CBD tem efeito sobre a amplitude do tremor na dose de 300 mg num modelo de ansiedade experimentalmente induzida em pessoas com DP;

$\checkmark$ A administração aguda de CBD na dose de 300mg se mostrou segura, sem efeitos adversos em pessoas com DP.

Estudos futuros poderiam avaliar os efeitos da administração crônica do CBD nos sintomas de ansiedade de pacientes com DP. Além disso, o uso de dispositivos como sensores de aceleração poderia ser útil na avaliação de sintomas motores de forma mais fidedigna, evitando a influência das flutuações motoras que podem ocorrer ao longo do dia. 


\section{REFERÊNCIAS}




\section{REFERÊNCIAS 1}

Allen, A.J., Leonard, H., Swedo, S.E. (1995). Current knowledge of medications for the treatment of childhood anxiety disorders. Journal of the American Academy of Child and Adolescent Psychiatry,34, 976-86.

Adams, R. (1940). Marihuana. Science. 92 (2380), 115-9.

Arjmand, S., Vaziri, Z., Behzadi, M., Abbassian, H., Stephens, G.J., Shabani, M. et al. (2015). Cannabinoids and Tremor Induced by Motor-related Disorders:Friend or Foe? Neurotherapeutics, 12(4), 778-787.

American Psychiatry Association. Diagnostic and Statistical Manual of Mental disorders DSM-5.(2013) 5th.ed. Washington: American Psychiatric Association.

Barbosa, M.T., Caramelli, P., Maia, D.P., Cunningham, M.C., Guerra, H.L., Lima-Costa, M.F. et al. (2006). Parkinsonism and Parkinson's disease in the elderly: a community-based survey in Brazil. Movement Disorders, 21(6), 800-8.

Barbosa, M.T., Caramelli, P,, Cunningham, M.C., Maia, D.P., Lima-Costa, M.F., Cardoso, F.(2013). Prevalence and clinical classification of tremor in elderly - a community based survey in Brazil. Movement Disorders, 28(5), 640-6.

Baptista, C.A. Estudo da prevalência do Transtorno de Ansiedade Social em estudantes universitários. Dissertação (Mestrado), Faculdade de Medicina, Universidade de São Paulo, Ribeirão Preto, 2006.

Bergamaschi, M.M., Queiroz, R.H., Chagas, M.H., de Oliveira, D.C., De Martinis, B.S., Kapczinski, F. (2011). Cannabidiol Reduces the Anxiety Induced by Simulated Public Speaking in Treatment-Naïve Social Phobia Patients.Neuropsychopharmacology, 36(6), 1219-1226.

\footnotetext{
${ }^{1}$ De acordo com o estilo APA - American PsychologicalAssociation
} 
Bergamaschi, M. M., Queiroz, R. H. C., Zuardi, A. W. \& Crippa, J. A. S. (2011). Safety and side effects of cannabidiol, a Cannabis sativa constituent. Current Drug Safety, 6(4), 23749.

Broen, M. P, Narayen, N.E., Kuijf M.L.; Dissanayaka N.N. \& Leentjens, A..F.(2016). Prevalence of anxiety in Parkinson's disease: A systematic review and meta analysis. Movement Disorders, 31(8), 1125-1133.

Broen, M. P., Köhler, S., Moonen, A. J., Kuijf, M. L., Dujardin, K., Marsh,.L et al. (2016). Modeling anxiety in Parkinson's disease. Movement Disorders, 31:310-6.

Belgrave, B.E., Bird, K.D., Chesher, G.B., Jackson, D.M., Lubbe, K.E., Starmer, G.A. et al. (1979). The effect of cannabidiol, alone and in combination with ethanol, on human performance. Psychopharmacology, 64, 243-246.

Bisogno, T., Hanus, L., De Petrocellis, L., Tchilibon, S., Ponde, D.E., Brandi I., Moriello, A.S., et al (2001). Molecular targets for cannabidiol and its synthetic analogues: effect onvanilloid VR1 receptors and on the cellular uptake and enzymatic hydrolysis ofanandamide. British Journal of Pharmacology, 134(4), 845-52.

Braak, H. \& DelTredici, K. (2008). Invited Article: Nervous system pathology in sporadic Parkinson disease.Neurology,70(20), 1916-25.

Bolluk, B., Özel-Kizil, E. T., Akbostanci, M. C., \& Atbasoglu, E. C. (2010). Social anxiety in patients with Parkinson's disease. The Journal of Neuropsychiatry and Clinical Neurosciences, 22, 390-394.

Booz, G.W. (2011). Cannabidiol as an emergent therapeutic strategy for lessening the impact of inflammation on oxidative stress. Free Radical Biology and Medicine, 51(5), 1054-61.

Bugalho, P., Lampreia, T., Miguel, R., Mendonça, M.D., Caetano, A., Barbosa, R. et al (2016). Non-Motor symptoms in Portuguese Parkinson's Disease patients: correlation and impact on Quality of Life and Activities of Daily Living. Scientific reports, 6(32267), 1-9. 
Blessing, E. M., Steenkamp, M.M., Manzanares, J. \& Marmar, C. R. (2015). Cannabidiol as a Potential Treatment for Anxiety Disorders.Neurotherapeutics, 12, 825-836.

Bhattacharyya, S., Morrison, P.D., Fusar-Poli, P., Martin-Santos, R., Borgwardt, S., WintonBrown,T.,et al. (2010). Opposite effects of delta-9-tetrahydrocannabinol and cannabidiol on human brain function and psychopathology. Neuropsychopharmacology, 35, 764-774.

Campos, A.C. \& Guimaraes F.S. (2008). Involvement of 5HT1A receptors in the anxiolyticlike effects of cannabidiol injected into the dorsolateral periaqueductal gray of rats. Psychopharmacology (Berl), 199, 223-30.

Campos, A.C., Moreira, F.A., Gomes, F.V., del Bel, E.A. \& Guimarães, F.S. (2012). Multiple mechanisms involved in the large-spectrum therapeutic potential of cannabidiol in psychiatric disorders. Philosophical Transactions of The Royal Society B Biological .367(1607), 3364-3378.

Campos, A. C., Fogaca, M. V., Sonego, A. B., \& Guimarães, F. S. (2016). Cannabidiol, neuroprotection and neuropsychiatric disorders. Pharmacology, 112, 119-127.

Carod-Artal, F.J., Ziomkowski, S., Mourão Mesquita, H. \& Martínez-Martin P.(2008). Anxiety and depression: main determinants of health-related quality of life in Brazilian patients with Parkinson's disease. Parkinsonism \& related disorders, 14(2), 102-108.

Castilho, A.R.G.L., Recondo, R., Asbahr,F.R, \& Manfro, G.G. (2000).Transtornos de ansiedade. Revista Brasileira de Psiquiatria,22 (Supl 2), 20-3.

Marcos, M. H. C., Tumas, V., Loureiro, S. R., Lemos, C., A.,C., Kawasaki, N. T. I., Crippa, J. A. S.et al (2009). Does the association between anxiety and Parkinson's disease really existature review. Current Psychiatry Reviews, 5, 29-36.

Chagas, M.H., Zuardi, A.W., Tumas, V., Pena-Pereira, M.A., Sobreira, E.T., Bergamaschi, M.M. et al. (2014). Effects of cannabidiol in the treatment of patients with Parkinson's disease: an exploratory double-blind trial. Journal of Psychopharmacology, 28(11): 10881098 .

Chagas, M. H. N., Oliveira, T.H.G.F., Linares, I.M.P., Balarini, F.B., Chagas, N.M.S., Tumas' V., Crippa' J.A.S. et al. (2017). Can anxiety increase tremors in patients with 
Parkinson's disease? An experimental model. Archives of Clinical Psychiatry (São Paulo), 44(4) 85- 88.

Cravatt, B.F., Giang, D.K., Mayfield, S.P., Boger, D.L, Lerner, R.A., Gilula, N.B.et al. (1996). Molecular characterization of an enzyme that degrades neuro modulatory fatty-acid amides. Nature, 384 (6604), 83-7.

Chuang, C. \& Fahn, S. (2001). Dramatic benefit with clonazepam treatment of intractable anxiety and panic attacks in Parkinson's disease. Movement Disorders, 16 (Suppl. 1), S35.

Chen J.J. \& Marsh L. (2014). Anxiety in Parkinson's disease: identification and management. Therapeutic Advances in Neurological Disorders,7(1), 52-9.

Connor, K.A., Feustel, P.J., Ramirez-Zamora, A., Molho, E., Pilitsis, J.G., Shin, D.S. et al. (2016). Investigation of diazepam efficacy on anxiety-like behavior in hemiparkinsonian rats. Behavioural Brain Research, 301 226-237.

Connolly B. \& Fox S.H. (2014). Treatment of cognitive, psychiatric, and affective disorders associated with Parkinson's disease. Neurotherapeutics, 11(1), 78-91.

Cui., S.S., Du, J.J., Fu, R., Lin, Y.K., Huang, P., He, Y.C. et al. (2017). Prevalence and risk factors for depression and anxiety in Chinese patients with Parkinson disease. BMC Geriatrics, 17, 270.

Cumming, R.\& Le Couteur, D. (2003) Benzodiazepines and risk of hip fractures in older people: a review of the evidence. CNS Drugs, 1, 825-837.

Chaudhuri, K. R. \& Schapira, A. H. V. (2009).Non-motor symptoms of Parkinson's disease: dopaminergic pathophysiology and treatment. Lancet Neurology, 8(5), 464-74.

Cheng, D., Spiro, A. S., Jenner, A. M., Garner, B. \& Karl, T. (2014b). Long-term cannabidiol treatment prevents the development of social recognition memory deficits in Alzheimer's 
disease transgenic mice. Journal of Alzheimer's Disease,42, 1383-1396.

Crippa, J.A., Zuardi, A.W., Garrido, G.E., Wichert-Ana, L., Guarnieri, R., Ferrari, L., AzevedoMarques, P.M., et al. (2004). Effects of cannabidiol (CBD) on regional cerebral blood flow. Neuropsychopharmacology, 29: 417-426

Crippa, J. A. S., Derenusson, G.N., Ferrari, T.B., Wichert-Ana, L., Duran, F.L., Martin-Santos, R. et al. (2011). Neural basis of anxiolytic effects of cannabidiol (CBD) in generalized social anxiety disorder: a preliminary report. Journal of Psychopharmacology, 25(1), 12130 .

Consroe, P., Laguna, J., Allender, J., Snider, S., Stern, L., Sandyk, R. et al. (1991). Controlled clinical trial of cannabidiol in Huntington's disease.Pharmacology, Biochemistry, and Behavior,40(3), 701-8.

Cunha, J. M., Carlini, E.A., Pereira, A.E., Ramos, O.L., Pimentel, C., Gagliardi, R. et al. (1980). Chronic administration of cannabidiol to healthy volunteers and epileptic patients. Pharmacology, 21(3), 175-85.

Dai, D., Zhang, P. \& Lueth, T.C. (2015). Quantitative Assessment of Parkinsonian Tremor Based on an Inertial Measurement Unit. Sensors, 15(10), 2555-2507.

Das, R.K., Kamboj, S.K., Ramadas, M., Yogan, K., Gupta, V., Redman, E. et al. (2013).Cannabidiol enhances consolidation of explicit fear extinction in humans. Psychopharmacology, 226, 781-792.

Dalgleish T. (2004). The Emotional brain. Nature Reviews Neuroscience, 5(7), 583-589.

Dalton, W.S., Martz, R.,Lemberger, L., Rodda, B.E.\&Forney R.B.(1976). Influence ofcannabidiol on delta-9-tetrahydrocannabinol effects. Clinical Pharmacology andTherapeutics, 19(3), 300-9.

Davis, M., Walker, D.L., Miles, L., \& Grillon, C. (2010). Phasic vs Sustained Fear in Rats and Humans: Role of the Extended Amygdala in Fear vs anxiety. Neuropsychopharmacology, 
$35,105-135$.

Devos, D., Dujardin, K., Poirot, I., Moreau, C., Cottencin, O., Thomas, P. et al. (2008). Comparison of desipramine and citalopram treatments for depression in Parkinson's disease: a double-blind, randomized, placebo-controlled study. Movement Disorders, 23(6), 850-7.

Delgado, M.R., Olsson, A \& Phelps' E. A. (2006). Extending animal models of fear conditioning to humans. Biological Psychology,73 (1), 39-48.

Di Marzo, V., Gobbi G., Szallasi A. (2008). Brain TRPV1: a depressing TR(i)P down memory lane? Trends in Pharmacological Sciences, 29:594-600.

Dinh, T.P., Carpenter, D., Leslie, F.M., Freund, T.F., Katona, I., Sensi, S.L. et al.(2012). Brain monoglyceride lipase participating in endocannabinoid inactivation. Proceedings of the National Academy of Sciences of the United States of America,99(16), 10819-24.

de Mello Schier, A.R., de Oliveira Ribeiro, N.P., Coutinho, D.S., Machado, S., Arias-Carrión, O., Crippa J.A. et al (2014). Antidepressant-like and anxiolytic-like effects of cannabidiol: a chemical compound of Cannabis sativa. CNS \& Neurological Disorders Drug Targets, 13(6), 953-60.

Dissanayaka, N.N., Sellbach, A., Matheson, S., O'Sullivan, J.D., Silburn, P.A., Byrne, G.J. et al. (2010). Anxiety disorders in Parkinson's disease: prevalence and risk factors. Movement Disorders, 25(7), 838-845.

Di Marzo, V., Bifulco, M., De Petrocellis, L. (2004). The endocannabinoid system and its therapeutic exploitation. Nature Reviews Drug Discovery,3(9), 771-84.

Donnelly, K., Bracchi, R., Hewitt, J., Routledge, P.A. \& Carter B. (2017). Benzodiazepines, Z drugs and the risk of hip fracture: A Systematic Review and Meta - Analysis. Plos One, 12(4).

Doder, M., Rabiner, E. A., Turjanski, N., Lees, A. J., Brooks, D. J., \& 11C-WAY 100635 PET study. (2003). Tremor in Parkinson's disease and serotonergic dysfunction: an 11C-WAY 100635 PET study. Neurology, 60(4), 601-5.

Duncan, G.W., Khoo, T.K., Yarnall, A. J., O'Brien, J.T., Coleman, S.Y., Brooks, D.J. et al (2014). Health related quality of life in early Parkinson's disease: The impact of nonmotor symptoms. Movement disorders, 29 (2), 195-202. 
Duvarci, S., \& Pare, D. (2014). Amygdala Microcircuits Controlling Learned Fear. Neuron, 82(5), 966-980.

Elble, R.J., Pullman, S.L., Matsumoto, J.Y., Raethjen, J., Deuschl, G., Tintner, R. et al (2006) Tremor Research Group. Tremor amplitude is logarithmically related to 4- and 5-point tremor rating scales. Brain, 129, 2660-2666.

Endler, N.S. \& Kocovski, N.L. (2001). State and trait anxiety revised. Anxiety Disorders, 15, 231-245.

Espejo-Porras, F., Fernández-Ruiz, J., Pertwee, R.G., Mechoulam, R. \& García, C. (2013). Motor effects of the non-psychotropic phytocannabinoid cannabidiol that are mediated by 5-HT1A receptors. Neuropharmacology, 75, 155-63.

Fahn, S. \& Elton, R. (1987). Unified Parkinson's disease Rating Scale (UPDRS). In S. Fahn, C. Marsden, D. Calne, \& n M. Goldstei (Eds.), Recent Developments in Parkinson's Disease.

Fan, J. Y., Chang, B. L. \& Wu, Y. R. (2016). Relationships among depression, anxiety, sleep, and quality of life in patients with Parkinson's disease in Taiwan. Parkinson's Disease. 18 .

Fernández - Ruiz. \& González, S. (2005). Cannabinoid Control of Motor Function at the Basal Ganglia. Cannabinoids. 168, 479-507.

Freud, S. (1927). The Ego and the Id. (JRiviere, trad., Hogarth Press e Instituto de Psicanálise). Londres.

Fusar-Poli, P., Crippa, J.A., Bhattacharyya, S., Borgwardt, S.J., Allen, P., Martin-Santos, R. et al. (2009). Distinct effects of \{delta\}9-tetrahydrocannabinol and cannabidiol on neural activation during emotional processing. Archives of General Psychiatry, 66(1), 95-105.

Georgiev, D., Hamberg, K., Hariz, M., Forsgren, L. \& Hariz G.M. (2017). Gender differences in Parkinson's disease: A clinical perspective Acta Neurologica Scandinavica, 136 (6), 570584. 
García-Arencibia, M., González, S., de Lago, E., Ramos, J.A., Mechoulam, R., FernándezRuiz, J. et al. (2007). Evaluation of the neuroprotective effect of cannabinoids in a rat model of Parkinson's disease: importance of antioxidant and cannabinoid receptorindependent properties. Brain Research, 1134(1), 162-70.

García-Arencibia, M., García, C., Kurz, .A., Rodríguez-Navarro, J.A., Gispert-Sáchez, S., Mena, M.A., Auburger, G. et al. (2009). Cannabinoid CB1 receptors are early downregulatedfollowed by a further upregulation in the basal ganglia of mice with deletion of specific parkgenes. Journal of Neural Transmission. Supplementum, (73), 269-75.

Gibb, W. R.\& Lees, A. J. (1988). The relevance of the Lewy body to the pathogenesis of idiopathic Parkinson's disease. Journal of Neurology, Neurosurgery, and Psychiatry, 51(6), 745-52.

Gibson J.D. (1994). What is the interpretation of spectral entropy? In: Proceedings of the IEEE IntSymp on Information Theory, p. 440.

Guimarães, F. S., Chiaretti, T. M., Graeff, F. G. \& Zuardi, A. W. (1990). Antianxiety effect of cannabidiol in the elevated plus-maze. Psychopharmacology, 100(4), 558-9.

Gomes, F. V., Resstel, L. B. M. \& Guimarães, F. S. (2011). The anxiolytic-like effects of cannabidiol injected into the bed nucleus of the stria terminalis are mediated by $5-\mathrm{HT} 1 \mathrm{~A}$ receptors. Psychopharmacology, 213(2-3), 465-473.

Glass, M., Dragunow, M. \& Faull, R.L. (1997). Cannabinoid receptors in the human brain: a de Tailed anatomical and quantitative autoradiographic study in the fetal, neonatal and adult human brain. Neuroscience, 77, 299-318.

Gong, H. Jr., Tashkin, D. P., Simmons, M. S., Calvarese, B., \& Shapiro, B. J. (1984). Acute and subacute bronchial effects of oral cannabinoids. Clinical Pharmacology \& Therapeutics,35, 26-32. 
Gordon, P.H., Pullman, S.L, Louis, E.D., Frucht, S.J. \& Fahn, S. (Mirtazapine in Parkinsonian tremor. Parkinsonism \& Related Disorders, 9(2):125-126.

Groenewegen H.J. (2003). The basal ganglia and motor control. Neural Plasticity, 10, 107-20.

Herkenham, M., Lynn, A.B., Little, M.D., Johnson, M.R., Melvin, L.S., de Costa, B.R. et al. (1990). Cannabinoid receptor localization in brain. Proceedings of the National Academy of Sciences of the United States of America, 87, 1932-1936.

Herkenham M., Lynn A.B., de Costa B.R. \& Richfield E.K. (1991b). Neuronal localization of cannabinoid receptors in the basal ganglia of the rat. Brain Research, 547:267-274.

Herkenham M. (1995). Localization of cannabinoid receptors in brain and periphery. In: Pertwee RG, editor. Cannabinoid receptors. London, Academic Press, 145-166.

Hoehn, M. M. \& Yahr, M. D. (1967). Parkinsonism: onset, progression and mortality. Neurology, 17, 427-442.

Hindocha, C., Freeman, T.P., Schafer, G, Gardener, C., Das, R.K., Morgan, C.J. et al (2015). Acute effects of delta- 9-tetrahydrocannabinol, cannabidiol and their combination on facial emotion recognition: a randomised, double-blind, placebo controlled study in cannabis users. European Neuropsychopharmacology, 25, 325-334.

Hampson, A. J., Grimaldi, M., Axelrod, J. \& Wink, D. (1998). Cannabidiol and (-)Delta9tetrahydrocannabinol are neuroprotective antioxidants. Proceedings of the National Academy of Sciences of the United States of America, 95(14), 8268-73.

Hofmann, S. G. \& Dibartolo, P. M. (2000). An instrument to assess self-statements during public speaking: scale development and preliminary psychometric properties. Behavior Therapy, 31(3), 499-515.

Hollister, L. E.\& Gillespie, H. (1975).Interactions in man of delta-9-tetrahydrocannabinol. II. Cannabinol and cannabidiol. Clinical Pharmacology and Therapeutics, 18(1), 80-3.

Hughes, A. J., Daniel, S. E., Kilford, L. \& Lees, A. J. (1992). Accuracy of clinical diagnosis 
of idiopathic Parkinson's disease: a clinico-pathological study of 100 cases. Journal of Neurology, Neurosurgery, and Psychiatry, 55(3), 181-4.

Huot, P., \& Fox, S. H. (2013). The serotonergic system in motor and non-motor manifestations of Parkinson's disease. Experimental Brain Research, 230(4), 463-476.

Hui, Y.P., Wang, T., Han, L.N., Li, L.B., Sun, Y.N., Liu, J., et al. (2015). Anxiolytic effects of prelimbic 5-HT(1A) receptor activation in the hemiparkinsonian rat. Behavioural Brain Research, 277:211-220.

Iffland, K. \& Grotenhermen, F. (2017). An Update on Safety and Side Effects of Cannabidiol: A Review of Clinical Data and Relevant Animal Studies. Cannabis and Cannabinoid Research. 2(1), 139-154.

Jadoon, K.A., Tan, G.D.O \& Sullivan, S.E. (2017). A single dose of cannabidiol reduces blood pressure in healthy volunteers in a randomized cross over study. JCI Insight, 2(11), 1-11.

Jang, W., Han, J., Park, J., Kim, J.S., Cho, J.W., Koh, S.B. et al. (2013). Wave form analysis of tremor may help to differentiate Parkinson's disease from drug-induced parkinsonism. Physiological Measurement, 34(3).

Jones, J.D., Butterfield, L.C., Song, W., Lafo, J., Manga, 1 P., Okun, M.S..et al. (2015). Anxiety and depression are better correlates of Parkinson's disease quality of life than apathy. The Journal of neuropsychiatry and clinical neurosciences, 27(3), 213-218.

Kathuria, S., Gaetani, S., Fegley, D., Valiño, F., Duranti, A., Tontini, A. et al. (2003). Modulation of anxiety through blockade of anandamide hydrolysis. Nature Medicine,9(1): 76-81.

Katona, I., Rancz, E.A., Acsady, L., Ledent, C., Mackie, K., Hajos, N. et al. (2001). Distribution of CB1 cannabinoid receptors in the amygdala and their role in the control of GABAergic transmission. Journal of Neuroscience, 21, 9506-9518.

Karniol, I.G., Shirakawa, I., Kasinski, N., Pfeferman, A. \& Carlini, E.A. (1974). Cannabidiol interferes with the effects of delta 9 - tetrahydrocannabinol in man. European Journal of Pharmacology, 28(1), 172-7.

Kempster, P. A., Hurwitz, B., \& Lees, A. J. (2007). A new look at James Parkinson's Essay 
on the Shaking Palsy. Neurology, 69(5), 482-5.

Kinrys, G. \& Wygant, L. E. (2005). Anxiety disorders in women: does gender matter to treatment? Revista Brasileira de Psiquiatria, 27, 43-50.

Lastres-Becker, I., Molina-Holgado, F., Ramos, J.A., Mechoulam, R. \& Fernández-Ruiz, J.(2005). Cannabinoids provide neuroprotection against 6-Hydroxydopamine toxicity in vivo and in vitro: relevance to Parkinson's disease. Neurobiology of Disease, 19(1-2), 96107.

Leentjens, A.F., Dujardin, K., Marsh, ., Martinez-Martin, P., Richard, I.H., Starkstein, S.E. et al. (2012). Anxiety and motor fluctuations in Parkinson's disease: a cross sectional observational study. Parkinsonism \& Related Disorders, 18(10), 1084-8.

Liu, W., Lin R., Yu, R., Tai, C., Lion C., Wu, R. et al. (2015). The impact of nonmotor symptoms on quality of life in patients with Parkinson's disease in Taiwan. Neuropsychiatric disease and treatment,11, 2865-2873.

Ligresti, A., De Petrocellis, L. \& Di Marzo, V. (2016). From phytocannabinoids to cannabinoid receptors and endocannabinoids: pleiotropic physiological and pathological roles through complex pharmacology. Physiological Reviews, 96, 1593-1659.

Louis, E. D., Marder, K., Cote, L., Wilder, D., Tang, M-X., Lantigua, R. et al. (1996). Prevalence of a history of shaking in persons 65 years of age andolder: diagnostic And functional correlates. Movement Disorders, 11(1), 63-9.

Lutz, S. G., Holmes, J. D., Ready, E. A., Jenkins, M. E., Johnson, A. M. (2016). Clinical Presentation of Anxiety in Parkinson's Disease: A Scoping Review: Occupation, Participation and Health, 36(3),134-147.

Martin, E. I., Ressler, K. J., Binder, E. \& Nemeroff, C.B. (2009). The Neurobiology of Anxiety Disorders: Brain Imaging, Genetics and Psychoneuroendocrinology .Psychiatric Clinics of North America,32(3), 549-575.

Martinez-Martin, P., Schapira, A.H., Stocchi, F., Sethi, K., Odin, P., MacPhee, G. et al (2007). Prevalence of nonmotor symptoms in Parkinson's disease in an international setting; study using nonmotor symptoms questionnaire in 545 patients. Movement Disorders, 22(11), 1623-9. 
McNair, D.M., Frankenthaler, L.M., Czerlinsky, T,, White, T.W., Sasson, S,, Fisher, S. et al. (1982). Simulated public speaking as a model of clinical anxiety. Psychopharmacology, 77(1), 7-10.

Mechoulam, R. \& Shvo, Y. (1963). Hashish. I. The structure of cannabidiol. Tetrahedron, 19(12), 2073-8.

Mecha, M., Feliú, A., Iñigo, P.M., Mestre, L., Carrillo-Salinas, F.J., Guaza, C..et al. (2013). Cannabidiol provides long-lasting protection against the deleterious effects of inflammationin a viral model of multiple sclerosis: A role for A2A receptors. Neurobiology of Disease, 59, 141-150.

Mincis, M., Pfeferman, A., Guimarães, R.X., Ramos, O.L., Zukerman, E., Karniol, I.G. et al (1973). Chronic administration of cannabidiol in man. Pilot study.AMB : Revista Da Associação Médica Brasileira, 19(5), 185-90.

Menza M, Marin H., Kaufman, K., Mark, M., \& Lauritano, M. (2004). Citalopram treatmentof depression in Parkinson's disease: the impact on anxiety, disability, and cognition. The Journal of Neuropsychiatry and Clinical Neurosciences , 16, 315-319.

Martin-Santos, R., Crippa, J.A., Batalla, A., Bhattacharyya, S., Atakan, Z., Borgwardt, S., Allen, P., Seal, M. et al. (2012). Acute effects of a single, oral dose of d9tetrahydrocannabinol (THC) and cannabidiol (CBD) administration in healthy volunteers. Current Pharmaceutical Design, 18, 4966-4979.

Micale, V., Di Marzo, V., Sulcova, A., Wotjak, C.T. \& Drago, F. (2013). Endocannabinoid system and mood disorders: priming a target for new therapies. Pharmacology \& Therapeutics, 138:18-37.

Mostile, G.J., Giuffrida, P., Adam, O.R., Davidson, A. \& Jankovic, J. (2010). Correlation between Kinesia system assessments and clinical tremor scores in patients with essential tremor movement. MovementDisorders, 25, 1938-1943.

Moriyama, T. S., Chagas,. M. H. N., Silveira-Moriyama, L., Tumas, V., Lees' A.J., Crippa, J.A. et al. (2016). Diagnosing social anxiety in Parkinson's disease: Characteristics and frequencies according to two diagnostic criteria. Revista de Psiquiatria Clínica, 43(6). 
Niazmand, K., Tonn, K., Kalaras, A., Fietzek, U. M., Mehrkens, J. H., Lueth, T. C. et al. (2011). Quantitative evaluation of Parkinson's disease using sensor based smart glove. In Proceedings of IEEE Symposium on Computer-Based Medical Systems, Bristol, UK, 27-30, 1-8.

Norris, H. (1971). The action of sedatives on brain stem oculomotor systems in man. Neuropharmacology, 10(21), 181-91.

Noreen, N., Muhammad, F., Akhtar, B., Azam, F. \& Anwar, M.I. (2018). Is Cannabidiol a Promising Substance for New Drug Development? A Review of its Potential Therapeutic Applications. Critical Reviews in Eukaryotic Gene Expression, 28(1), 73-86.

Osório, F. L., Crippa, J. A. S. \& Loureiro, S. R. (2013). Validation of the state version of The Self-Statement during Public Speaking Scale. Revista Brasileira de Psiquiatria (São Paulo, Brazil, 35(1), 63-6.

Ohno Y., (2011). Therapeutic role of 5-HT1A receptors in the treatment of schizophrenia and Parkinson's disease. CNS Neuroscience\&Therapeutics, 17, 58-65.

Parkinson J. (2016). Um ensaio sobre a paralisia agitante. Revista Latino americana de Psicopatologia,19(1), 122-149.

Patel, S., Hill, M.N., Cheer, J.F., Wotjak, C.T., Holmes, A. (2017). The endocannabinoid systemas a target for novel anxiolytic drugs. Neuroscience and Biobehavioral Reviews, 76 $56-66$.

Pertwee, R. G. (2008). The diverse CB1 and CB2 receptor pharmacology of three plant cannabinoids: Delta9-tetrahydrocannabinol, cannabidiol and delta9tetrahydrocannabivarin. British Journal of Pharmacology, 153, 199-215.

Peres, F. F., Lima, A. C., Hallak, J. E. C., Crippa, J. A., Silva, R. H., Abílio, V.C. et al (2018). Cannabidiol as a promising strategy to treat and prevent movementdisorders? Frontiers in Pharmacology, 9, 1-12. 
Pisanti, S., Picardi, P., D'Alessandro, A., Laezza, C. \& Bifulco, M. (2013). The endocannabinoid signaling system in cancer. Trends in Pharmacological Sciences, 34, 273-282.

Pisanti, S., Malfitano, A.M., Ciaglia, E., Lamberti, A., Ranieri, R., Cuomo, G. et al. (2017). Cannabidiol: State of the art and new challenges for therapeutic applications. Pharmacology \& Therapeutics, 175,133-150.

Pontone, G. M., Williams, J. R., Anderson, K. E., Chase, G., Goldstein, .S. A., Grill, S. et al. (2009). Prevalence of anxiety disorders and anxiety subtypes in patients with Parkinson's disease. Movement Disorders, 24(9), 1333-1338.

Pontone, G. M., Williams, J. R., Anderson, K. E., Chase, G., Goldstein, S. R., Grill S. et al. (2011). Anxiety and self-perceived health status in Parkinson's disease. Parkinsonism \& Related Disorders, 17(4), 249-254.

Pontone, G.M., Williams, J.R., Anderson, K.E., Chase, G., Goldstein, S,R., Grill, S. et al. (2013). Pharmacologic treatment of anxiety disorders in Parkinson's disease. The American Association for Geriatric Psychiatry, 21(6):520-528.

Ponti, M., Bet, P., Oliveira, C. L. \& Castro, P. C. (2017). Better than counting seconds: Identifying fallers among healthy elderly using fusion of accelerometer features and dualtask Timed Up and Go. PLoS one, 12(4), e0175559.

Poewe, W. (2008). Non-motor symptomsin Parkinson's disease. European Journal of Neurology, 15 (Suppl.1), 14-20.

Pull, C. B. (2012). Current status of knowledge on public-speaking anxiety. Current opinion in Psychiatry, 25(1), 32-38.

Quelhas, R. \& Costa, M. (2009). Anxiety, depression, and quality of life in Parkinson's disease. The Journal of neuropsychiatry and clinical neurosciences, 21(4), 413-419.

Rahman, S., Griffin, H. J., Quinn, N. P. \& Jahanshahi, M. (2008). Quality of life in Parkinson's disease: the relative importance of the symptoms. Movement Disorders, 23(10), 14281434. 
Remes, O., Brayne, .C, van der Linde, R. \& Lafortune, L. (2016). A Systematic Review of Reviews on the Prevalence of Anxiety Disorders in Adult Populations. Brain and Behavior,6 (7).

Rodríguez-Violante, M., de Saráchaga, A. J., Cervantes-Arriaga, A., Davila-Avila, N. M., Carreón-Bautista, E., Estrada-Bellmann, I. et al. (2017). Premotor symptoms and the risk of Parkinson's disease: A case-control study in Mexican population. Clinical Neurology and Neurosurgery. 160, 46-49.

Ribeiro, A., Almeida, V.I., Costola-de-Souza, C., Ferraz-de-Paula, V., Pinheiro, M. L., Vitoretti, L. B. et al., (2015). Cannabidiol improves lung function and inflammation in mice submitted to LPS-induced acute lung injury. Immunopharmacology and Immunotoxicology, 37, 35-41.

Rocha, F. C., Dos Santos Júnior, J. G., Stefano, S. C. \& da Silveira, D. X. (2014). Systematic review of the literature on clinical and experimental trials on the antitumor effects of cannabinoids in gliomas. Journal of Neuro-Oncology, 116, 11-24.

Ruiz, P. J. G., Bernardos, V. S., Bartolomé, M. \& Torres, A. G. (2007). Capit timed tests quantify age-related motor decline in normal subjects. Journal of the Neurological Sciences, 260(1-2), 283-5.

Russo, E. B., Burnett, A., Hall, B. \& Parker, K. K. (2005). Agonistic properties of canabidiol at 5-HT1a receptors. Neurochemical Research, 30(8), 1037-43.

Saito, V.M., Wotjak, C.T. \& Moreira, F.A. (2010). Exploração farmacológica do sistema endocanabinoide: novas perspectivas para o tratamento de transtornos de ansiedade e depressão? Revista Brasileira de Psiquiatria, 32 (1).

Sagar, D. R., Gaw, A.G., Okine, B. N., Woodhams, S. G., Wong, A., Kendall, D. A., et al. (2009). Dynamic regulation of the endocannabinoid system: implications for analgesia. Molecular Pain. 5, 59.

Sagna A., Gallo J.J. \& Pontone, G.M. (2014). Systematic review of factors associated with depression and anxiety disorders among older adults with Parkinson's disease. Parkinsonism \& Related Disorders, 20(7): 708-715. 
Salazar, R.D., Le, A.M., Neargarder, S. \& Cronin-Golomb, A. (2017). The impact of motor symptoms on self-reported anxiety in Parkinson's disease, Parkinsonism \& Related Disorders, 38:26-30.

Schwab R. S. \& England A. C. Projection technique for evaluating surgery in Parkinson's disease. In Gillingham F. J., Donaldson M. C. (1969) editors, Third Symposium on Parkinson's Disease Edinburgh, E \& S Livingstone, 152-157.

Schneider, F., Althaus, A., Backes, V. \& Dodel, R. (2008). Psychiatric symptoms in Parkinson's disease. European Archives of Psychiatry and Clinical Neuroscience, 258(5), 55-9.

Swedo, S. E., Leonard, H. L. \& Allen, A. J. (1994). New developments in childhood affective and anxiety disorders. Current Problems in Pediatrics, 24, 12-38.

Scott, K. A., Dalgleish, A. G. \& Liu,W. M. (2014). The combination of cannabidiol and $\Delta 9$ tetrahydrocannabinol enhances the anticancer effects of radiation in an orthotopic murine glioma model. Molecular Cancer Therapeutics, 13, 2955-2967.

Scuderi, C., Steardo, L., \& Esposito, G. (2014). Cannabidiol promotes amyloid precursor protein ubiquitination and reduction of beta amyloid expression in SHSY5YAPP+ cells through PPAR $\gamma$ involvement. Phytotherapy Research, 28, 1007-1013.

Schenkman, M.L., Clark, K., Xie, T., Kuchibhatla, M., Shinberg, M,, Ray, L. et al. (2001). Spinal movement and performance of standing reach task in participants with and without Parkinson disease. Physical Therapy, 81, 1400-11.

Spielberger, C.D. (1979). Understanding Stress and Anxiety.Harper and Row, New York.

Svíženská, I., Dubový, P. \& Šulcová, A. (2008). Cannabinoid receptors 1 and 2 (CB1 and CB2), their distribution, ligands and functional involvement in nervous system structures - Ashort review. Pharmacology Biochemistry and Behavior, 90(4), 501-511.

Stanley, C. P., Hind, W. H. \& O'Sullivan, S. E. (2013). Is the cardiovascular system a therapeutic target for cannabidiol? British Journal of Clinical Pharmacology, 75, 313-322.

Sun, Y.N., Wang, T., Wang, Y., Han, L.N., Li, L.B., Zhang, Y.M. et al. (2015). Activation of 5-HT1A receptors in the medial subdivision of the central nucleus of the amygdala 
produces anxiolytic effects in a rat model of Parkinson's disease. Neuropharmacology, 95,181-191.

Sultan, S.R., Millar, S.A., England, T.J. \& O'Sullivan, S.E. (2017). A Systematic Review and Meta-Analysis of the Haemodynamic Effects of Cannabidiol. Frontiers Pharmacology, 24; $8: 81$.

Thomas, A., Baillie, G.L., Phillips, A.M., Razdan, R.K., Ross, R.A., Pertwee, R.G. et al (2007). Cannabidiol displays unexpectedly high potency as an antagonist of CB1 and CB2 receptor agonist in vitro. British, Journal of Pharmacology, 150(5), 61 -23.

Tandberg, E., Larsen, J. P., Aarsland, D. \& Cummings, J. L. (1996). The occurrence of depression in Parkinson's disease: a community-based study. Archives of Neurology, 53(2) $175-179$.

Vriend, C, Boedhoe, P.S., Rutten, S., Berendse, H.W., van der Werf, Y.D., van den Heuvel, O.A. et al. (2016). A smaller amygdala is associated with anxiety in Parkinson'sdisease:a combined FreeSurfer-VBM study. Journal of Neurology, Neurosurgery, and Psychiatry, $87(5), 493-500$.

Wolters Kluwer Health (2012). Selective Serotonin Reuptake Inhibitors. Drug Facts and Comparisons. Facts \& Comparisons ${ }^{\circledR}$ [database online]. St Louis: Wolters Kluwer Health. Recuperado Agosto 30, 2018, de https://wolterskluwer.com/

Weintraub, D. \& Burn, D. J. (2011). Parkinson's Disease: The Quintessential Neuropsychiatric Disorder. Movement Disorders : Official Journal of the Movement Disorder Society, 26(6), 1022-1031.

Wiedemann, K. (2015). Anxiety and Anxiety Disorders. International Encyclopedia of the Social \& Behavioral Sciences, 2(1), 805-810.

Witjas, T., Kaphan, E., Azulay, J.P., Blin, O., Ceccaldi, M., Pouget, J., et al (2002). Nonmotor fluctuations in Parkinson's disease Frequent and disabling. Neurology, 59(3), 408-413.

Wile, D. J., Ranawaya, R., \& Kiss, Z. H. T. (2014). Smart watch accelerometry for analysis and diagnosis of tremor. Journal of Neuroscience Methods, 230, 1-4.

World Health Organization (2018). ICD-11 for Mortality and Morbidity Statistics (ICD-11 MMS) 2018 version . Recuperado Julho 20, 2018, de https://icd.who.int/browse11/l-m/en. 
Yamanishi, T., Tachibana, H., Oguru, M., Matsui, K., Toda, K., Okuda, B. et al. (2013). Anxiety and depression in patients with Parkinson's disease. Internal Medicine, 52(5), 539-545.

Zuardi, A. W. \& Karniol, I. (1981). Estudo Transcultural de uma Escala de Auto-avaliação para estados subjetivos. Jornal Brasileiro De Psiquiatria, 31, 403-496.

Zuardi, A. W., Shirakawa, I., Finkelfarb, E. \& Karniol, I. G. (1982). Action of cannabidiol on the anxiety and other effects produced by delta 9-THC in normal subjects. Psychopharmacology, 76(3), 245-50.

Zuardi, A. W., Cosme, R. A., Graeff, F. G. \& Guimarães, F. S. (1993). Effects of ipsapirone and cannabidiol on human experimental anxiety. Journal of Psychopharmacology, 7(1), $82-8$.

Zuardi, A. W. (2006). History of cannabis as a medicine: a review. Revista Brasileira de Psiquiatria, 28(2), 153-7.

Zuardi, A. (2008). Cannabidiol: from na active cannabinoid to a drug with wide spectrum of action. Revista Brasileira de Psiquiatria, 30(3), 271-80.

Zuardi, A. W., Crippa, J. A., Hallak, J. E., Pinto, J. P., Chagas, M. H., Rodrigues, G. G. et al. (2009). Cannabidiol for the treatment of psychosis in Parkinson's disease. Journal of Psychopharmacology, 23(8), 979-83.

Zuardi, A. W., Rodrigues, N. P., Silva, A. L., Bernardo, S. A., Hallak, J. E. C., Guimarães, F.S., Crippa, J. A. S. et al. (2017). Inverted U-Shaped Dose-Response Curve of the Anxiolytic Effect of Cannabidiol during Public Speaking in Real Life. Frontiers in Pharmacology, 8,259. 
APÊNDICES 


\section{APÊNDICES}

Apêndice A - Questionário de caracterização do sujeito

\section{IDENTIFICACÃO}

Nome:

Endereço:

Numero:

Complemento:

CEP: Bairro:

Telefone : $(\quad)$ e-mail:

\section{DADOS SOCIODEMOGRÁFICOS}

Nascimento: __________ Idade:

Sexo:(1) Masculino(2) Feminino

\begin{tabular}{|l|l|}
\hline Situação Conjugal: & Escolaridade \\
\hline ( 1 ) Solteiro & (1) Analfabeto(a) \\
\hline ( 2 ) Divorciado & (2) $1^{\text {o Grau incompleto }}$ \\
\hline (3 ) Viúvo & (3) $1^{\text {o Grau completo }}$ \\
\hline (4 ) Amasiado/ Casado & (4) $2^{\text {o Grau incompleto }}$ \\
\hline & (5) $2^{\text {o Grau completo }}$ \\
\hline & (6) Ensino Superior completo \\
\hline & (7) Ensino Superior incompleto \\
\hline & (8) Pós Graduação \\
\hline
\end{tabular}

Profissão/Ocupação:

Aposentado?( ) Sim （ ) Não

\begin{tabular}{|c|c|}
\hline $\begin{array}{c}\text { O(A) sr(a) possui alguma doença? } \\
\text { ( ) Sim ( ) Não }\end{array}$ & $\begin{array}{c}\text { Quais são os medicamentos que o(a) sr faz } \\
\text { Se sim, cite-as ? }\end{array}$ \\
\hline & \\
\hline & \\
& \\
\hline
\end{tabular}


Apêndice B - Termo de Consentimento Livre e Esclarecido

NOME DA PESQUISA: Efeitos da administração aguda do Canabidiol na ansiedade e nos tremores induzidos pelo teste de simulação de falar em público em pacientes com doença de Parkinson

PESQUISADOR RESPONSÁVEL: Marcos Hortes NisiharaChagasCREMESP: 121.844

(disponível no período do estudo e 48 horas após o experimento)

tel.: (016) 98145-2367

\section{Justificativa e objetivo da pesquisa}

Vários estudos mostram que uma substância extraída da planta Cannabis sativa, chamada canabidiol poderia agir nos sintomas de sua doença. Você está sendo convidado(a) a participar deste estudo cujo objetivo é avaliar como o Canabidiol atua nas medidas de ansiedade e tremores em uma situação de ansiedade.

\section{Procedimentos que serão utilizados e seu objetivo.}

Este estudo é composto de duas partes. Nesta primeira parte, você receberá uma cápsula contendo Canabidiol ou uma cápsula com farinha (placebo). Na sequência, você deverá preencher escalas para nos dizer como você está se sentindo naquele momento. Estas escalas são bastante simples e nós faremos um treinamento antes de iniciar os testes. Também mediremos sua pressão arterial e seu pulso. Após, fixaremos dois pequenos equipamentos denominados acelerômetros nos dedos de sua mão. Este equipamento será utilizado para medir os tremores de sua mão. Algumas vezes, quando as pessoas ficam nervosas, as mãos ficam suadas, o coração pode bater mais rápido, as mãos podem tremer. No final desta primeira parte, eu lhe explicarei a segunda metade do estudo e você me dirá se deseja continuar participando do estudo ou não. 0 tempo total desta parte é de mais ou menos 20 minutos. Estas avaliações ocorrerão no departamento de Gerontologia da Universidade Federal de São Carlos no Laboratório de Práticas Gerontológicas.

\section{Desconfortos e riscos esperados.}

O Canabidiol é um dos cerca de 400 componentes da Cannabis sativa, masnãoé o componente responsável pelos efeitos psicológicos comumente observados com a cannabis em humanos. O canabidiol já foi estudado em outras pessoas e não apresentou efeitos indesejáveis a não ser sonolência em doses muito altas. Outros possíveis riscos do estudo são o possível desconforto e cansaço em realizar os testes e responder às perguntas propostas. Além disso, mesmo que pequena, há possibilidade de outras pessoas terem acesso às informações que você ofereceu.

Caso você sinta algum desconforto nas próximas 48 horas, você poderá entrar em contato com o pesquisador responsável de nossa equipe para uma avaliação. Caso você se sinta incomodado, nós poderemos interromper os procedimentos, se assim você desejar. No final desta primeira parte, eu lhe explicarei a segunda metade do estudo e você me dirá se deseja continuar participando do estudo ou não.

\section{Benefícios que se pode obter}

A sua participação no estudo poderá contribuir para que possamos compreender a ação do Canabidiol perante situações que causem ansiedade em portadores de doença de Parkinson. 
Além disso, caso seja encontrada qualquer alteração nas suas avaliações você será informado, orientado e encaminhado para um tratamento adequado. 


\section{TERMO DE CONSENTIMENTO PÓS INFORMAÇÃO (segunda parte)}

\section{NOME DA PESQUISA: Efeitos da administração aguda do Canabidiol na ansiedade e nos tremores induzidos pelo teste de simulação de falar em público em pacientes com doença de Parkinson}

PESQUISADOR RESPONSÁVEL: Marcos Hortes NisiharaChagasCREMESP: 121.844

(disponível no período do estudo e 48 horas após o experimento)

tel.: (016) 98145-2367

\section{Justificativa e objetivo da pesquisa}

Conforme eu havia lhe dito anteriormente, estamos interessados em verificar o efeito do canabidiolsobre a ansiedade e tremores induzidos por meio do teste de simulação ao falar em público em voluntários com doença de Parkinson.

\section{Procedimentos que serão utilizados e seu objetivo.}

Caso você decida participar do estudo, será pedido para você realizar um discurso sobre o sistema de transporte de sua cidade.Você terá 2 minutos para preparar o discurso, que deverá ter uma duração de 4 minutos. Este discurso será gravado em vídeo e depois analisado pelos pesquisadores.

Durante e após a realização do discurso sobre o sistema de transporte, você deverá responder novamente a mesma escala e mediremos sua pressão arterial e seu pulso, como fizemos na primeira parte do estudo. Os dois equipamentos que medem seus tremores também continuarão fixos em seus dedos. Estas avaliações ocorrerão no departamento de Gerontologia da Universidade Federal de São Carlos no Laboratório de Práticas Gerontológicas.

\section{Desconfortos e riscos esperados.}

Como possíveis riscos do estudo, cita-se o possível desconforto e cansaço em realizar os testes e responder às perguntas propostas, que exigem engajamento do participante. Além disso, a duração total do estudo é de mais ou menos 2 horas. Por último, mesmo que pequena, há possibilidade de outras pessoas terem acesso às informações que você ofereceu.

Preparar e realizar o discurso não apresenta riscos para sua saúde, porém você pode sentir desconforto por causa da ansiedade. Caso você sinta incomodado com isso durante a sessão experimental, poderemos conversar sobre isso, e caso você continue a se sentir muito incomodado interromperemos a atividade, se você assim desejar.

\section{Benefícios que se pode obter}

A sua participação no estudo poderá contribuir para que possamos compreender a ação do Canabidiol perante situações que causem ansiedade em portadores de doença de Parkinson.

Além disso, caso seja encontrada qualquer alteração nas suas avaliações você será informado, orientado e encaminhado para um tratamento adequado. 
$\mathrm{Eu}$

R.G. abaixo assinado, tendo recebido as informações acima, e ciente dos meus direitos abaixo relacionados, concordo em participar.

1. A garantia de receber a resposta a qualquer pergunta ou esclarecimento a qualquer dúvida acerca dos procedimentos, riscos, benefícios e outros relacionados com a pesquisa a que serei submetido;

2. A garantia de assistência integral e indenização em caso de danos decorrentes da minha participação no estudo;

3. A liberdade de retirar meu consentimento a qualquer momento e deixar de participar no estudo sem que isso traga prejuízo à continuidade de qualquer tratamento que tenho neste serviço;

4. A segurança de que não serei identificado e que será mantido o caráter confidencial da informação relacionada com a minha privacidade;

5. O compromisso de me proporcionar informação atualizada durante o estudo, ainda que esta possa afetar minha vontade de continuar participando;

6. O compromisso de que serei devidamente acompanhado e assistido durante todo o período de minha participação no projeto pelo responsável pela pesquisa;

7. O ressarcimento de eventuais despesas como transporte e alimentação decorrentes da minha participação no projeto estão previstos no orçamento da pesquisa,portanto será dada uma ajuda de custo no valor de $\mathrm{R} \$ 20,00$ (vinte reais) para cobrir estes gastos;

8. Que o ressarcimento de eventuais despesas, bem como a indenização, a título de cobertura material, para reparação de danos imediatos e tardios, decorrentes de minha participação na pesquisa, estão previsto no orçamento da pesquisa, não cabendo ao Departamento de Gerontologia da Universidade Federal de São Carlos qualquer responsabilidade quanto aos referidos pagamentos.

Declaro, ainda, que concordo inteiramente com as condições que me foram apresentadas e que, livremente, manifesto a minha vontade em participar do referido projeto.

São Carlos, de de

\section{ASSINATURA DO PACIENTE}

ASSINATURA DO PESQUISADOR RESPONSÁVEL

Marcos Hortes Nisihara Chagas CRM-SP: 121.844

Telefone para contato por 48h: (16) 98145-2367

(Emitido em 2 vias) 
ANEXOS 


\section{ANEXOS}

Anexo A - Escala Self-Statements during Public Speaking - Tapping Test

Por favor, imagine as coisas que você costuma pensar sobre si mesmo, quando se encontra em alguma situação em que tenha que falar em público. Tendo em mente essas situações, até que ponto você concorda com as afirmações a seguir? Por favor, dê uma nota de 0 (se discorda totalmente) a 5 (se você concorda inteiramente com a afirmação)

\begin{tabular}{|c|c|c|c|c|c|c|}
\hline 1. O que tenho a perder ? Vale a pena tentar & 0 & 1 & 2 & 3 & 4 & 5 \\
\hline 2. Sou um fracasso & 0 & 1 & 2 & 3 & 4 & 5 \\
\hline 3. Esta é uma situação difícil, mas posso dar conta dela & 0 & 1 & 2 & 3 & 4 & 5 \\
\hline $\begin{array}{l}\text { 4. Um fracasso nesta situação seria mais uma prova de } \\
\text { minha incompetência }\end{array}$ & 0 & 1 & 2 & 3 & 4 & 5 \\
\hline 5. Mesmo que não dê certo, não é o fim do mundo & 0 & 1 & 2 & 3 & 4 & 5 \\
\hline 6. Posso dar conta de tudo & 0 & 1 & 2 & 3 & 4 & 5 \\
\hline 7. Qualquer coisa que eu disser vai parecer bobagem & 0 & 1 & 2 & 3 & 4 & 5 \\
\hline 8. Acho que vou me dar mal de qualquer jeito & 0 & 1 & 2 & 3 & 4 & 5 \\
\hline $\begin{array}{l}\text { 9. Em vez de me preocupar, poderia me concentrar no } \\
\text { que quero fazer }\end{array}$ & 0 & 1 & 2 & 3 & 4 & 5 \\
\hline $\begin{array}{l}\text { 10. Eu me sinto desajeitado e tolo, certamente eles vão } \\
\text { notar }\end{array}$ & 0 & 1 & 2 & 3 & 4 & 5 \\
\hline
\end{tabular}

\section{TAPPING TEST}

10 ciclos/tempo: Direita: _(s.) Esquerda:_____(s.)

\section{MEDIDA DA ANSIEDADE (FISIOLÓGICA)}

FC: PA: 
Anexo B-Escala Analógica Visual de Humor

SUJEITO:

FASE:.....

INSTRUÇÕES: Avalie como você se sente agora em relação aos itens abaixo e marque cada linha com um traço vertical no ponto que melhor descreve seus sentimentos. O centro de cada linha indica como você habitualmente se encontra e as extremidades indicam o máximo de cada condição.

ALERTA

SONOLENTO

CALMO

AGITADO

FORTE

FRACO

CONFUSO

COM IDÉIAS CLARAS

ÁGIL

DESAJEITADO

APÁTICO

DINÂMICO

SATISFEITO

INSATISFEITO

PREOCUPADO

TRANQUILO

RACIOCÍNIO

DIFÍCIL

PERSPICAZ

TENSO

ATENTO

INCAPAZ

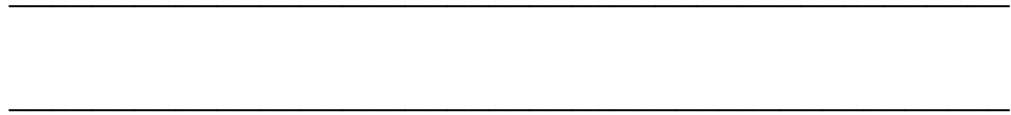

ALEGRE

HOSTIL

INTERESSADO

RELAXADO

DISTRAÍDO

CAPAZ

TRISTE

AMISTOSO

DESINTERESSADO

RETRAÍDO

SOCIÁVEL 
Anexo C-Unified Parkinson's Disease Rating Scale

\section{UPDRS}

I.PENSAMENTO, COMPORTAMENTO E HUMOR ( ${ }^{*}$ informações obtidas pela anamnese)

\section{COMPROMET. INTELECTUAL}

\section{$0=$ Nenhum}

$1=$ Leve. Esquecimento consistente, mas com recordação parcial dos eventos e sem outras dificuldades.

2=Moderada perda de memória, com desorientação e dificuldade moderada em lidar com problemas complexos. Comprometimento leve, mas definitivo, das funções em casa com eventual necessidade de auxílio.

3=Acentuada perda de memória com desorientação temporal e freqüentemente espacial. Acentuado comprometimento na capacidade de lidar com problemas.

4=Grave perda de memória, com preservação da orientação apenas para pessoas. Incapaz de fazer julgamentos ou de resolver problemas. Precisa de muita ajuda para os cuidados pessoais. Nunca pode ser deixado sozinho.

\section{DISTÚRBIOS DO PENSAMENTO}

$0=$ Nenhum

$1=$ Sonhos vívidos.

2=Alucinações "benignas" com crítica preservada ("insight").

3=Alucinações ou delírios ocasionais a freqüentes, com perda da crítica ("sem insight"). Podem interferir com as atividades diárias.

4=Alucinações persistentes, delírios ou psicose "florida". Incapaz de se cuidar sozinho.

\section{DEPRESSÃO}

$0=$ Ausente

$1=$ Períodos de tristeza ou sensação de culpa maior que o normal, nunca persistentes por dias ou semanas.

$2=$ Depressão persistente (1 semana ou mais).

$3=$ Depressão persistente com sintomas vegetativos (insônia, anorexia, perda de peso, perda de interesse).

4=Depressão persistente com sintomas vegetativos e pensamentos ou tentativas de suicídio.

\section{MOTIVAÇÃO E INICIATIVA}

$0=$ Normal.

$1=$ Menos afirmativo que habitualmente, mais passivo.

$2=$ Perda da iniciativa ou desinteresse por atividades eletivas (não-rotineiras).

$3=$ Perda da iniciativa ou desinteresse pelas atividades do dia-a-dia (rotineiras)

4= Isolamento, perda completa de motivação.

\section{ATIVIDADES DA VIDA DIÁRIA}

\begin{tabular}{|l|l|l|}
\hline 5. FALA & ON & OFF \\
\hline $0=$ Normal. & & \\
\cline { 2 - 3 } & & \\
\cline { 2 - 3 }
\end{tabular}

$1=$ Levemente comprometida. Sem dificuldade para ser compreendido.

2=Moderadamente comprometida. Algumas vezes é solicitado a repetir suas frases.

$3=$ Acentuadamente comprometida. Freqüentemente é solicitado a repetir suas frases.

$4=$ Ininteligível a maior parte do tempo.

\begin{tabular}{|l|l|l|}
\hline 6. SALIVAÇÃO & ON & OFF \\
\hline \multirow{2}{*}{$0=$ Normal } & & \\
\cline { 2 - 3 }
\end{tabular}

$1=$ Discreto, mas definitivo aumento de saliva na boca, pode babar dormindo.

$2=$ Moderado excesso de saliva, pode babar um pouco.

$3=$ Acentuado excesso de saliva com baba.

$4=$ Baba muito, precisa usar constantemente um lenço ou toalha.

\begin{tabular}{|l|l|l|}
\hline 7. DEGLUTIÇÃO & ON & OFF \\
\hline \multirow{2}{*}{$0=$ Normal } & & \\
\cline { 2 - 3 } & &
\end{tabular}

$1=$ Engasga raramente

$2=$ Engasga ocasionalmente

$3=$ Necessita de alimentos pastosos

4= Necessita alimentar-se por sonda ou gastrostomia

\begin{tabular}{|l|l|l|}
\hline 8. ESCRITA & ON & OFF \\
\hline $0=$ Normal. & & \\
\cline { 2 - 3 }
\end{tabular}

$1=$ Discreto alentecimento ou redução do tamanho da escrita (micrografia).

2=Moderado alentecimento ou redução do tamanho da escrita, todas as palavras são legíveis.

$3=$ Acentuadamente comprometida, nem todas as palavras são legíveis.

4=A maioria das palavras não é legível

\begin{tabular}{|l|l|l|l|}
\hline $\begin{array}{l}\text { 9. CORTAR ALIMENTOS E } \\
\text { MANUSEAR UTENSÍLIOS }\end{array}$ & ON & OFF \\
\cline { 1 - 2 } $0=$ Normal & & \\
\cline { 2 - 4 }
\end{tabular}

$1=$ Pouco lento e desajeitado, mas não precisa de auxílio.

$2=$ Pode cortar a maioria dos alimentos embora seja lento e desajeitado, necessita de algum auxílio.

$3=0$ alimento precisa ser cortado por outra pessoa, mas ainda pode se alimentar sozinho vagarosamente.

4=Precisa ser alimentado

\begin{tabular}{ll|l|l|}
\hline 10. VESTIR-SE & ON & OFF \\
\hline $\begin{array}{l}0=\text { Normal } \\
1=\text { Lento, mas não necessita de }\end{array}$ & & \\
auxílio.
\end{tabular}

2=Ocasionalmente necessita de auxílio para abotoar-se e enfiar os braços nas mangas das camisas

$3=$ Precisa de ajuda considerável, mas pode vestir algumas peças sozinho.

4=Dependente

\begin{tabular}{|l|l|l|}
\hline 11. HIGIENE & ON & OFF \\
$\begin{array}{l}0=\text { Normal } \\
1=\begin{array}{l}\text { Lento, mas não necessita de } \\
\text { auxílio. }\end{array}\end{array}$ & & \\
\cline { 2 - 3 }
\end{tabular}

$2=$ Necessita de ajuda no banho, ou é muito lento na sua higiene pessoal. 
$3=$ Precisa de ajuda para lavar-se, escovar os dentes, pentear os cabelos, ir ao banheiro.

4=Usa sonda vesical ou outros dispositivos

\begin{tabular}{|l|l|l|l|}
$\begin{array}{l}\text { 12. VIRAR-SE E AJUSTAR A } \\
\text { ROUPA DE CAMA }\end{array}$ & ON & OFF \\
\cline { 1 - 3 } $0=$ normal & & \\
\cline { 2 - 3 }
\end{tabular}

$1=$ um pouco lento e desajeitado, mas não precisa de auxílio.

$2=$ pode virar-se na cama sozinho ou ajeitar os lençóis, mas tem grande dificuldade.

$3=$ pode iniciar os movimentos, mas não é capaz de virarse na cama ou ajeitar os lençóis sem auxílio.

$4=$ dependente

\begin{tabular}{l|l|l|}
$\begin{array}{l}\text { 13. QUEDAS (não relacionadas ao } \\
\text { "freezing") }\end{array}$ & ON & OFF \\
\hline $\begin{array}{l}0=\text { não cai } \\
1=\text { quedas muito raras }\end{array}$ & & \\
\cline { 2 - 4 }
\end{tabular}

2 = quedas ocasionais, menos que 1 vez ao dia.

$3=$ cai em média uma vez ao dia

$4=$ cai mais de uma vez ao dia

\begin{tabular}{|c|c|c|}
\hline $\begin{array}{l}\text { 14. CONGELAMENTO AO ANDAR } \\
\text { ("freezing") }\end{array}$ & ON & OFF \\
\hline $0=$ não há & & \\
\hline
\end{tabular}

$1=$ congelamento raro durante a marcha, pode hesitar para iniciar a marcha.

$2=$ congelamentos ocasionais durante a marcha.

$3=$ congelamentos freqüentes. Ocasionalmente cai por causa do congelamento.

$4=$ quedas freqüentes pelo congelamento

\begin{tabular}{|l|l|l|}
\hline 15. MARCHA & ON & OFF \\
\hline \multirow{2}{*}{$0=$ Normal } & & \\
\cline { 2 - 3 } & &
\end{tabular}

$1=$ Leve dificuldade. Pode não balançar os braços ou tende a arrastar a perna

$2=$ Dificuldade moderada, mas precisa de pouca ou nenhuma ajuda.

3= Distúrbio acentuado da marcha precisa de auxílio.

$4=$ Não consegue andar mesmo com ajuda

\begin{tabular}{l|l|l|}
$\begin{array}{l}\text { 16. TREMOR } \\
\text { (em qualquer parte do corpo) }\end{array}$ & ON & OFF \\
$\begin{array}{l}0=\text { Ausente } \\
\begin{array}{l}\text { 1= Discreto e presente raramente } \\
$\cline { 2 - 3 }\end{array}\end{array} & \\
\hline
\end{tabular}

$2=$ Moderado, é incômodo ao paciente.

$3=$ Acentuado, interfere com muitas atividades

4= Grave, interfere com a maioria das atividades.

\begin{tabular}{|lr|l|l|}
\hline 17. QUEIXAS & SENSORIAIS & ON & OFF \\
\cline { 4 - 5 } RELACIONADAS & AO & & \\
PARKINSONISMO & & & \\
\hline
\end{tabular}

$0=$ Ausentes

$1=$ Ocasionalmente tem dormências, formigamentos, ou dor leve.

$2=$ Freqüentemente tem dormências, formigamentos, ou dor leve, mas que não são aflitivos.

$3=$ Sensações dolorosas freqüentes.

\section{EXAME MOTOR}

\begin{tabular}{|l|l|l|}
\hline 18. FALA & ON & OFF \\
\hline $0=$ Normal & & \\
\cline { 2 - 3 } & &
\end{tabular}

$1=$ Leve perda da expressão, dicção ou volume.
2=Monótona, enrolada, mas comprometimento moderado

é compreensível,

$3=$ Comprometimento acentuado, difícil de compreender. 4= Ininteligível.

\begin{tabular}{|l|l|l|}
\hline 19. EXPRESSÃO FACIAL & ON & OFF \\
\hline $0=$ Normal & & \\
\cline { 2 - 3 }
\end{tabular}

$1=$ Hipomimia mínima, poderia ser uma face normal ("poker face").

$2=$ Hipomimia leve, mas com redução definitiva da expressão facial.

$3=$ Hipomimia moderada, lábios entreabertos durante parte do tempo.

4= Fáscies fixa ou "em máscara", com perda acentuada ou completa da expressão facial, lábios entreabertos.

\begin{tabular}{|c|c|c|c|}
\hline \multicolumn{2}{|l|}{ 20. TREMOR DE REPOUSO } & ON & OFF \\
\hline \multirow{5}{*}{$\begin{array}{l}0=\text { Ausente } \\
1=\text { Discreto e presente raramente } \\
2=\text { De pequena amplitude e } \\
\text { persistente, ou moderada } \\
\text { amplitude mas intermitente. } \\
\text { 3=Moderada amplitude e presente } \\
\text { a maior parte do tempo } \\
4=\text { Grande amplitude e presente a } \\
\text { maior parte do tempo }\end{array}$} & FACE & & \\
\hline & MSD & & \\
\hline & MSE & & \\
\hline & MID & & \\
\hline & MIE & & \\
\hline \multicolumn{2}{|c|}{$\begin{array}{l}\text { 21. TREMOR POSTURAL/AÇÂO DAS } \\
\text { MÃ̃) }\end{array}$} & ON & OFF \\
\hline \multirow{2}{*}{$\begin{array}{l}0=\text { Ausente } \\
1=\text { Discreto, presente com a ação. } \\
2=\text { Moderada amplitude, presente } \\
\quad \text { com a ação. }\end{array}$} & MSD & & \\
\hline & MSE & & \\
\hline
\end{tabular}

.3= Moderada amplitude, presente durante a manutenção da postura e com a ação.

4= Acentuada amplitude, interfere com a alimentação.

\begin{tabular}{|c|c|c|c|}
\hline \multicolumn{2}{|l|}{ 22. RIGIDEZ } & ON & OFF \\
\hline \multirow{5}{*}{$\begin{array}{l}0=\text { Ausente } \\
1=\text { Leve ou detectada apenas } \\
\text { quando ativada por } \\
\text { movimentos "em espelho" } \\
\text { ou outros movimentos. } \\
2=\text { Leve a moderada } \\
3=\text { Acentuada, mas se consegue } \\
\text { facilmente toda amplitude } \\
\text { do movimento. }\end{array}$} & pescoço & & \\
\hline & MSD & & \\
\hline & MSE & & \\
\hline & MID & & \\
\hline & MIE & & \\
\hline
\end{tabular}

$4=$ Grave, a amplitude total do movimento é conseguida com dificuldade.

\begin{tabular}{|l|l|l|l|}
\hline \multicolumn{2}{|l|}{ 23. BATIDA DOS DEDOS } & ON & OFF \\
\hline $\begin{array}{l}\text { O= Normal } \\
1=\text { Leve lentificação e/ou redução } \\
\text { na amplitude }\end{array}$ & MSD & & \\
\cline { 2 - 4 } & MSE & & \\
\cline { 2 - 4 }
\end{tabular}


2=Comprometimento moderado. Fadiga nítida e precoce. Pode apresentar ocasionais interrupções do movimento

3=Comprometimento acentuado. Há freqüente hesitação em iniciar o movimento ou interrupções durante a sua execução

$4=\mathrm{Mal}$ consegue executar a tarefa

\begin{tabular}{|c|c|c|c|}
\hline \multicolumn{2}{|c|}{$\begin{array}{l}\text { 24. MOVIMENTO DE ABRIR E FECHAR } \\
\text { AS MÃOS }\end{array}$} & ON & OFF \\
\hline \multirow{2}{*}{$\begin{array}{l}0=\text { Normal } \\
1=\quad \text { Leve lentificação e/ou } \\
\text { redução na amplitude }\end{array}$} & MSD & & \\
\hline & MSE & & \\
\hline
\end{tabular}

$2=$ Comprometimento moderado. Fadiga nítida e precoce. Pode apresentar ocasionais interrupções do movimento

3= Comprometimento acentuado. Há freqüente hesitação em iniciar o movimento ou interrupções durante a sua execução

$4=$ Mal consegue executar a tarefa

\begin{tabular}{|c|c|c|c|}
\hline \multicolumn{2}{|l|}{ 25. PRONAÇÃO E SUPINAÇÃO } & ON & OFF \\
\hline \multirow{2}{*}{$\begin{array}{l}0=\text { Normal } \\
1=\text { Leve lentificação e/ou redução } \\
\text { na amplitude }\end{array}$} & MSD & & \\
\hline & MSE & & \\
\hline
\end{tabular}

$2=$ Comprometimento moderado. Fadiga nítida e precoce. Pode apresentar ocasionais interrupções do movimento

$3=$ Comprometimento acentuado. Há freqüente hesitação em iniciar o movimento ou interrupções durante a sua execução

4= Mal consegue executar a tarefa

\begin{tabular}{|l|l|l|l|}
\hline \multicolumn{2}{|l|}{ 26. AGILIDADE DAS PERNAS } & ON & $\begin{array}{l}\text { O } \\
\text { FF }\end{array}$ \\
\hline $\begin{array}{l}\text { 0= Normal } \\
\text { 1= Leve lentificação e/ou redução } \\
\text { na amplitude }\end{array}$ & MID & & \\
\cline { 2 - 4 } & & & \\
2= Comprometimento moderado. Fadiga nítida e precoce. \\
Pode apresentar ocasionais interrupções do \\
movimento \\
3= Comprometimento acentuado. Há freqüente hesitação \\
em iniciar o movimento ou interrupções durante a \\
sua execução
\end{tabular}
4= Mal consegue executar a tarefa

\begin{tabular}{|l|l|l|}
\hline 27. LEVANTAR DA CADEIRA & ON & OFF \\
\hline $0=$ normal & & \\
\cline { 2 - 3 }
\end{tabular}

$1=$ É lento, ou pode ter que tentar mais de uma vez.

$2=$ Precisa se apoiar nos braços da cadeira ou segurar-se na mesa à frente para se levantar

$3=$ Tende a cair para trás e pode ter que tentar mais de uma vez, mas consegue se levantar sem auxílio.

4= Incapaz de levantar-se sem auxílio

\begin{tabular}{|l|l|l|}
\hline 28. POSTURA & ON & OFF \\
\hline \multirow{2}{*}{$0=$ Normal, ereta. } & & \\
\cline { 2 - 3 } & &
\end{tabular}

$1=$ Não completamente ereta, discretamente curvada, poderia ser normal para idosos.

$2=$ Postura moderadamente curvada, definitivamente anormal. Pode estar levemente desviado para um lado.
$3=$ Postura acentuadamente curvada com cifose, pode estar moderadamente desviado para um lado.

$4=$ Flexão acentuada com anormalidade extrema da postura

\begin{tabular}{|l|l|l|}
\hline 29. MARCHA & ON & OFF \\
\cline { 1 - 3 } $0=$ Normal & & \\
\cline { 2 - 3 } & &
\end{tabular}

$1=$ Anda lentamente, pode arrastar os pés com passos curtos mas não há festinação ou propulsão.

$2=$ Anda com dificuldade, mas precisa de pouco ou nenhum auxílio; pode ter alguma festinação, passos curtos ou propulsão.

$3=$ Acentuado distúrbio da marcha, necessita auxílio.

$4=$ Não pode andar mesmo com auxílio.

\begin{tabular}{|l|l|l|}
\hline 30. ESTABILIDADE POSTURAL & ON & OFF \\
\hline $0=$ Normal. & & \\
\cline { 2 - 3 }
\end{tabular}

$1=$ Retropulsão, mas se recupera sem auxílio

$2=$ Ausência de resposta postural, poderia cair se não fosse seguro pelo examinador.

$3=$ Muito instável, tende a perder 0 equilíbrio espontaneamente.

$4=$ Incapaz de ficar em pé sem auxílio.

\begin{tabular}{|l|l|l|l|}
\hline $\begin{array}{l}\text { 31. BRADICINESIA } \\
\text { HIPOCINESIA CORPORAL }\end{array}$ & ON & OFF \\
\cline { 1 - 3 } $0=$ Nenhuma & & \\
\cline { 2 - 3 } & &
\end{tabular}

1= Mínimo alentecimento, dando ao movimento um aspecto deliberado, poderia ser normal para algumas pessoas. Possível redução da amplitude

$2=$ Discreto alentecimento e pobreza dos movimentos que é definitivamente anormal. Ou, redução nítida na amplitude dos movimentos.

$3=$ Moderado alentecimento, pobreza nos movimentos, ou movimentos de pequena amplitude.

$4=$ Acentuado alentecimento, pobreza nos movimentos, ou movimentos de pequena amplitude.

IV. COMPLICACÕES DA TERAPIA

(considerar a semana anterior à consulta)

\section{A. DISCINESIAS}

32. DURAÇÃO: As discinesias ocupam qual proporção do tempo total do seu dia?(dados de anamnese)

$\square 0=$ Nenhuma

$\square 1=1-25 \%$ do dia

$\square 2=26-50 \%$ do dia

$\square 3=51-75 \%$ do dia

$\square$ 4= $76-100 \%$ do dia

33. INCAPACIDADE: quanto que as suas discinesias são incapacitantes?(dados de anamnese que podem ser modificados pelo exame clínico)

$\square 0=$ Não incapacitantes

$\square 1=$ Levemente incapacitantes

$\square 2=$ Moderadamente incapacitantes

$\square 3=$ Acetuadamente incapacitantes

$\square 4=$ Completamente incapacitantes

\section{$\square$ INTENSIDADE}

$\square 0=$ ausente 
$\square 1=$ leves

$\square 2=$ moderadas

$\square 3=$ acentuadas

$\square 4=$ muito acentuadas

34. DISCINESIAS DOLOROSAS: Quanto que as suas discinesias são dolorosas?

$\square 0=$ Não há discinesias dolorosas

$\square 1=$ Levemente dolororas

$\square 2=$ Moderadamente dolorosas

$\square 3=$ Acentuadamente dolorosas

$\square$ 4= Gravemente dolorosas

35. PRESENÇA DE DISTONIA MATINAL? (anamnese)

$\square 0=$ Não

$\square 1=\operatorname{Sim}$

\section{B. FLUTUAÇÕES CLÍNICAS}

36. O paciente tem períodos de "off" previsíveis (deterioração-de-fim-de-dose)?

$\square 0=$ Não

$\square 1 \mathrm{a}=\operatorname{Sim}$, após cerca de 4 horas após a última dose

$\square 1 \mathrm{~b}=$ Sim, após cerca de 2 a 3 horas após a última dose

$\square 1 \mathrm{c}=\operatorname{Sim}$ após cerca de 1 a 2 horas após a última dose

$\square 1 d=$ Sim após menos de 1 hora após a última dose

37. O paciente tem períodos de "off" imprevisíveis (fenômeno on-off)?

$\square 0=$ Não

$\square 1=\operatorname{Sim}$

38. Qualquer período "off" se instala repentinamente, em poucos segundos?

$\square 0=$ Não

$\square 1=\operatorname{Sim}$

39. Em média, qual a proporção do dia em que o paciente permanece em "off"?

$\square 0=$ Nenhuma

$\square 1=1-25 \%$ do dia

$2=26-50 \%$ do dia

$\square 3=51-75 \%$ do dia

$\square 4=76-100 \%$ do dia

\section{OUTRAS COMPLICAÇÕES}

40. O paciente tem anorexia, náuseas e vômitos?

$\square 0=$ Não

$\square 1=\mathrm{Sim}$

41. O paciente tem distúrbios do sono,?

$\square 0=$ Não

$\square 1 \mathrm{a}=\mathrm{Sim}$, insônia

$\square 1 \mathrm{~b}=$ Sim, hipersonolência diurna

$\square 1 \mathrm{c}=$ Sim, distúrbio comportamental do sono REM

$\square 1 \mathrm{~d}=$ Sim, acinesia noturna

$\square 1 \mathrm{e}=\operatorname{Sim}$, síndrome das pernas inquietas

$\square 1 \mathrm{f}=\mathrm{Sim}$, movimentos periódicos do sono

$\square 1 \mathrm{~g}=\mathrm{Sim}$, sonambulismo

$\square 1 \mathrm{~h}=\mathrm{Sim}$, sonilóquio

42. O paciente tem hipotensão ortostática sintomática?

(medir PA sentado e em pé)

$\square 0=$ Não

$\square 1=\operatorname{Sim}$
PRESSÃO ARTERIAL

\begin{tabular}{|l|l|}
\hline Sentado ( $>5 \mathrm{~min})$ & \\
\hline Em pé (>2 min) & \\
\hline
\end{tabular}

43. Tem constipação? (evacua < 4x/semana, ou precisa fazer força ou usar laxantes para evacuar?) $\square 0=$ Não $\square 1=$ Sim

44. Tem urgência miccional?

$\square 0=$ Não $\square 1=\operatorname{Sim}$

45. Tem nictúria?

$\square 0=$ Não $\square 1=$ Sim

46. Perdeu o olfato ou o paladar?

$\square 0=$ Não $\square 1=$ Sim

47. Tem sudorese excessiva?

$\square 0=$ Não $\square 1=\operatorname{Sim}$

48. Tem interesse exagerado por sexo?

$\square 0=$ Não $\square 1=\operatorname{Sim}$

49. Tem interesse anormal por jogo ou coleções? $\square 0=$ Não $\square 1=$ Sim 
Anexo D-Hoehn \&Yahr

\begin{tabular}{lll}
\hline V. ESTADIO & $\begin{array}{l}\text { ESCALA MODIFICADA DE } \\
\text { HOEHN \& YAHR: }\end{array}$ \\
\hline $\mathbf{O N}$ & OFF & \\
\hline$\square \mathbf{0}$ & $\square \mathbf{0}$ & Ausência de sinais da doença \\
\hline$\square \mathbf{1}$ & $\square \mathbf{1}$ & Doença unilateral \\
\hline$\square \mathbf{1 , 5}$ & $\square \mathbf{1 , 5}$ & Doença unilateral mais envolvimento axial \\
\hline$\square \mathbf{2}$ & $\square \mathbf{2}$ & $\begin{array}{l}\text { Doença bilateral sem alteração do } \\
\text { equilíbrio postural }\end{array}$ \\
\hline$\square \mathbf{2 , 5}$ & $\square \mathbf{2 , 5}$ & $\begin{array}{l}\text { Doença bilateral leve com recuperação no } \\
\text { teste de estabilidade postural }\end{array}$ \\
\hline$\square \mathbf{3}$ & $\square \mathbf{3}$ & $\begin{array}{l}\text { Doença bilateral leve a moderada, alguma } \\
\text { instabilidade postural, independente. }\end{array}$ \\
\hline$\square \mathbf{4}$ & $\square \mathbf{4}$ & $\begin{array}{l}\text { Incapacidade acentuada, ainda capaz de } \\
\text { andar ou levantar-se sem auxílio. }\end{array}$ \\
\hline$\square \mathbf{5}$ & $\square \mathbf{5}$ & $\begin{array}{l}\text { Limitado à cadeira de rodas ou à cama, } \\
\text { exceto se auxiliado. }\end{array}$ \\
\hline
\end{tabular}


Anexo E - Escala de atividades diárias de Schwab \& England

\begin{tabular}{|c|c|c|}
\hline \multicolumn{3}{|c|}{$\begin{array}{l}\text { VI. ESCALA DE ATIVIDADES DIÁRIAS DE } \\
\text { SCHWAB \& ENGLAND }\end{array}$} \\
\hline ON & OFF & \\
\hline $\begin{array}{l}100 \% \\
\square\end{array}$ & $\begin{array}{l}100 \% \\
\square\end{array}$ & $\begin{array}{l}\text { Completamente independente. Capaz } \\
\text { de realizar todas as atividades sem } \\
\text { lentidão, dificuldade } \\
\text { comprometimento. Essencialmente } \\
\text { normal. Inconsciente de qualquer } \\
\text { dificuldade. }\end{array}$ \\
\hline $\begin{array}{l}90 \% \\
\square\end{array}$ & $\begin{array}{l}90 \% \\
\square\end{array}$ & $\begin{array}{l}\text { Completamente independente. Capaz } \\
\text { de realizar todas as atividades com } \\
\text { algum grau de lentidão ou dificuldade. } \\
\text { Pode demorar o dobro. Começando a } \\
\text { perceber as dificuldades. }\end{array}$ \\
\hline $\begin{array}{l}80 \% \\
\square\end{array}$ & $\begin{array}{l}80 \% \\
\square\end{array}$ & $\begin{array}{l}\text { Completamente independente na } \\
\text { maioria das atividades. Gasta o dobro do } \\
\text { tempo. Consciente da dificuldade e } \\
\text { lentidão }\end{array}$ \\
\hline $\begin{array}{l}70 \% \\
\square\end{array}$ & $\begin{array}{l}70 \% \\
\square\end{array}$ & $\begin{array}{l}\text { Não completamente independente. Maior } \\
\text { dificuldade em algumas atividades. Tres a } \\
\text { quatro vezes mais demorado em algumas. } \\
\text { Pode gastar grande parte do dia com as } \\
\text { atividades da vida diária. }\end{array}$ \\
\hline
\end{tabular}

$60 \% \quad 60 \%$ Alguma dependência. Pode realizar a maioria das atividades, embora seja excessivamente lento e precisar se esforçar muito. Algumas atividades são impossíveis

\begin{tabular}{llll}
\hline $\mathbf{5 0} \%$ & $\mathbf{5 0 \%}$ & $\begin{array}{l}\text { Mais dependente. Necessita de auxílio na metade } \\
\text { das atividades, lento. Dificuldade com tudo. }\end{array}$ \\
$\square$ & $\square$ & \\
\hline $\mathbf{4 0 \%}$ & $\mathbf{4 0 \%}$ & $\begin{array}{l}\text { Muito dependente. Pode participar de todas } \\
\text { atividades, mas realiza poucas sozinho. }\end{array}$ & \\
$\square$ & $\square$ &
\end{tabular}

$\mathbf{3 0} \% \quad 30 \% \quad$ Com muito esforço pode iniciar, ou realizar, apenas $\square \quad \square \quad$ algumas atividades sozinho. Necessita de muito auxílio.

\begin{tabular}{lll}
\hline $\mathbf{2 0} \%$ & $\mathbf{2 0} \%$ & $\begin{array}{l}\text { Nada realiza sozinho. Pode participar um pouco em } \\
\text { algumas atividades. Invalidez acentuada }\end{array}$ \\
$\square$ & $\square$ & \\
\hline $\mathbf{1 0 \%}$ & $\mathbf{1 0 \%}$ & Totalmente dependente. Completamente inválido \\
$\square$ & $\square$ & \\
\hline $\mathbf{0 \%}$ & $\mathbf{0 \%}$ & $\begin{array}{l}\text { Não mantém funções vegetativas como deglutição, } \\
\text { função vesical e intestinal. Confinado ao leito }\end{array}$ \\
$\square$ & $\square$ & .
\end{tabular}


